\title{
Estado del Arte de la Gestión administrativa: Avances y Retos para las Empresas Colombianas del Sector de la Construcción
}

\author{
Págs. 83 - 108
}

Grupo de Investigación: Centro de investigación en competitividad empresarial

Línea de investigación: competitividad de empresas constructoras

Rodrigo Andrés Ruiz Medina•

\section{RESUMEN}

El presente documento, realiza una muy resumida aproximación a las prácticas, modelos, metodologías y cuerpos de conocimiento desarrollados en Administración, relativos a la Gestión y Desarrollo Organizacional, para determinar cuáles de éstos han sido implementados o acogidos por la Gerencia de Empresas constructoras. Posterior a dicha revisión, se identificó que metodologías como el modelo de $\mathrm{Ne}$ gocios, el Startup liviano, el desarrollo de clientes, el diseño de experiencias, y otras, no se han aplicado, según la literatura consultada, como prácticas en la Gerencia de Empresas Constructoras. Con estos resultados, se realizó una consulta a expertos para determinar el potencial uso de dichas metodologías en el sector constructivo, obteniendo resultados alentadores para las metodologías analizadas.

Palabras Clave: Gerencia, Gestión, Construcción, Metodologías, Modelos, Prácticas, Validación.

\section{ABSTRACT}

This document makes a very brief approach to practices, models, methodologies and developed bodies of knowledge in Administration, related to the Man- agement and Organizational Development, to determine which of these, have been implemented or received by the Management of construction companies. After such review, it was identified that methodologies such as the business model, the lean Startup, customer development, experience design, and others have not been applied, according to the literature, such practices Management of Construction Companies. With these results, it became an expert consultation to determine the potential use of these methodologies in the construction sector, obtaining encouraging results for the tested methodologies.

Keywords: Management, Construction Management, Methodologies, Models, Practices Validation

\section{INTRODUCCIÓN}

Hoy en día, las empresas que pertenecen al Sector de la Construcción adolecen de una ausencia de metodologías propias para la Gestión y la Administración, que afectan de múltiples formas el desempeño general. El presente documento, es el resultado de una primera fase exploratoria que pretende caracterizar las prácticas de

\footnotetext{
- Ph. D. (c) Rodrigo Andrés Ruiz Medina. Docente Investigador programa Especialización en Gerencia de Empresas Constructoras. Fundación Universidad de América. rodrigo.ruiz@investigadores.uamerica.edu.co
} 
Gestión y Administración Modernas como modelos, metodologías, y técnicas que hayan surgido en los últimos quince años, explorando un poco las raíces históricas, y tendencias que han impulsado su evolución, para luego determinar la posible aplicabilidad de éstas a la Gestión de Empresas Constructoras en Bogotá.

Se espera que con éste y otros estudios posteriores, se puedan desarrollar o proponer prácticas de Gestión propias para la Administración de Empresas que pertenezcan éste Sector.

Este Documento de trabajo, tiene la siguiente estructura:

En una Primera fase se aborda de una manera muy general la problemática de la Administración actual, los Modelos y Metodologías de Gestión Moderna, en donde se exploran las raíces Históricas, tendencias principales y prácticas surgidas después del año 2000.

En la Segunda parte, se bordan las Prácticas de Gestión identificadas en la Gerencia de Empresas Constructoras, en donde se plasman modelos técnicas y metodologías que ya se han incorporado en diferentes escenarios globales, y que sirven como insumo para el estado del arte del objeto de estudio (Gerencia de Empresas Constructoras)

En la tercera parte se realiza un Análisis de Expertos, en donde se describe la opinión de un grupo de expertos en Gestión de Empresas acerca del grado de aplicabilidad que tienen algunas de las prácticas de gestión actuales a la Gerencia de Empresas Constructoras en Bogotá.

Finalmente, y a manera de conclusión, se analizan algunas oportunidades y tendencias investigativas futuras para este objeto de estudio.

\section{METODOLOGÍA}

METODOLOGÍA UTILIZADA: Para definir la pertinencia de algunas prácticas de gestión identificadas, se acudió a la metodología de consulta de expertos. A través de ésta, se esperaba definir cuáles de las prácticas que aún no han sido desarrolladas en el Sector de las Empresas Constructoras, podían tener un alto potencial en dicho sector.

PARTICIPANTES: Debido a ciertas restricciones, se acudió a tres expertos en los campos de la Construcción, la Administración de Empresas y la consultoría de Empresas con experiencia en implementación de modelos y metodologías testeadas a nivel Global, para que desde ésta triple óptica, se obtuvieran resultados relativamente objetivos.

PROCEDIMIENTO: Para el desarrollo de este ejercicio se construyó un instrumento de recolección de información con base en las prácticas que aún no han sido desarrolladas en el Sector. Y con base en éste, se realizaron entrevistas a profundidad, y ejercicios de consensos y disensos para identificar de manera concreta y de acuerdo con la opinión de éstos expertos, algunas nuevas prácticas de gestión a ser implementadas en el sector.

\section{2. ¿CUÁL ES EL PROBLEMA DE LA ADMINISTRACIÓN?}

Esta pregunta representa una de las cuestiones académicas de mayor debate en las ciencias sociales y ha generado una gran riqueza intelectual a lo largo de las diferentes escuelas o corrientes de pensamiento desde la década de 1920, dado que ésta, implícitamente encierra otras preguntas que han generado múltiples puntos de vista, como por ejemplo, ¿qué es una organización? ¿Teoría administrativa es lo mismo que Teoría organizacional?, ¿cuál es el rol de un Gerente o Administrador?, ¿Cuáles deben ser sus funciones?, ¿Qué debería procurar la Administración en las Organizaciones?

El concepto organización posee dos connotaciones dentro del ámbito administrativo, la primera hace referencia a la habilidad de poner 
LÍNEA DE INVESTIGACIÓN: COMPETITIVIDAD DE EMPRESAS CONSTRUCTORAS

en orden una serie de elementos, y la segunda hace referencia a un esquema estructurado de varios sistemas (Social, tecnológico, cultural etc.) que son susceptibles de ser administrados. Esta diferenciación, hace ver que la Teoría Organizacional y la Teoría Administrativa son diferentes dado que la primera tiene un enfoque de análisis de estructuras sociales y se enfoca en la necesidad imperiosa de entender, describir y predecir su conducta, y la segunda hace referencia la susceptibilidad que tienen las Organizaciones (sistemas sociales) de ser ordenados lógicamente, a través de una serie de etapas, incorporando una serie de principios, reglas y normas, y tratando de describir y explicar la conducta particular de cada administrador, junto con su habilidad para hacer transitar a la Organización a través de las diferentes etapas (planeación, organización, coordinación, dirección y control).

Hay dos enfoques según (Bertoglio, 1982). El enfoque tradicional que centra sus esfuerzos en un enclave más normativo y el enfoque decisional que se centra en lo descriptivo, y en la expresión entre variables.

Con base en lo anterior se puede entender que un enfoque, está mucho más orientado a la toma de decisiones que afectan la conducta del grupo humano perteneciente a la Organización, con el fin de alcanzar objetivos que éste, ha establecido.

(Simon, 1965) es el pionero de esta línea de pensamiento, y enfatiza en que la acción administrativa o el rol de un Gerente, se centra en la toma de decisiones, y se compone de varias etapas: La formulación del problema, la fijación de criterios de decisión, la búsqueda de alternativas, y la elección de una de ellas. Y aunque algunos autores se refieran a esta posición como una "simplificación peligrosa" (Levitt, 1974), otros la defienden (Bertoglio, 1982) dada la profunda complejidad de los sistemas objetocliente presentes en las organizaciones, y la "intransferibilidad" del ejecutivo entre empresas que el mismo Levitt sostiene.
El enfoque tradicional por su parte, surge desde los aportes que de manera temprana hicieron Taylor y Fayol (H. F. Taylor, 1911) que como semilla de un cumulo de raíces teóricoempíricas, sentaron los principios de la administración, y desencadenaron un proceso de construcción normativo-reglamentario que ha sido perpetuado y enriquecido sistemáticamente por diversas escuelas de pensamiento, derivando en un enfoque mucho más Directivo

\section{Confusión entre Dirección y Gestión:}

La dirección hace referencia a la definición de objetivos básicos y fijación de grandes directrices o líneas de acción administrativa que definen el marco de acción y el plan general, mientras de la gestión hace referencia a la conducta diaria y a la ejecución de las operaciones corrientes regida por objetivos y directrices brindadas por la Dirección.

Y dado que el enfoque descriptivo, ha tenido como principal insumo el análisis de la actividad cotidiana, y se ha centrado más en la gestión del día a día, la toma de decisiones genera tensión entre estas dos posturas dado que una primera categoría tiene que ver con elementos políticos y otra con elementos operacionales, unos proceden de la estrategia y otros de la rutina, y ello ha generado un conflicto sutil en cuanto a la clase de poder que cada grupo de decisiones inviste.

\section{La administración debería procurar:}

Entender a la Organización como un sistema abierto, con múltiples propósitos e interacciones a diferentes niveles de decisión y acción entre sus subsistemas y su entorno, recursos básicos, procesos esenciales, vínculos de articulación entre procesos, subsistemas e intersistemas, comunicación, división, supervisión y control, impronta de identidad como totalidad,

Es sabido que la administración tiene un robusto pero fragmentado linaje, dado que ha sido nutrida por diferentes doctrinas que le han 
realizado innumerables aportes ampliamente diversificados y con puntos de convergencia singulares. $Y$ en este camino, ha procurado su independencia como práctica profesional, logrando avances significativos en la construcción de un cuerpo de conocimiento propio que cada vez le permite estar más cerca de una filosofía de la ciencia o Teoría General de Administración, pero para ello, debe resolver primero algunos de los principales problemas que han planteado diversos autores antes de lograr tan anhelada unificación.

\section{¿Cuál es el verdadero problema?}

En este aparte, se van a presentar algunos de los más discutidos problemas en la administración dado que no es el principal enfoque de este documento, sino más bien un abrebocas para la caracterización del fenómeno.

Un primer problema es que la Administración tiene como objeto principal la dirección de organizaciones con fenomenologías complejas pero con una caja instrumental que ha sido diseñada desde sus orígenes con un enfoque simplista dada la elevada presencia de procesos rutinarios en ésta, y dada la coyuntura de ser éstos los primeros en ser detectados.

El profesor Le Moigne (1997), deja explícito el problema de la ausencia de un método propio en las ciencias de la Gestión, y la dificultad que ha tenido a la hora de legitimar sus saberes epistemológicos dados los múltiples intentos que han realizado, pero que han sido catalogados como "incoherentes" por académicos positivistas

Ted Levitt (1974) deja sobre la mesa el problema de la "Intransferibilidad" del directivo, haciendo referencia a la imposibilidad que tiene un directivo que se desarrolla en un sector económico particular, de desarrollarse con el mismo nivel de éxito, si se hiciera transferencia de éste profesional a un nuevo ámbito o sector económico de trabajo. Y esta discusión radica en la ausencia de una Teoría General Unificada para la Administración y la Gestión.
Existe una predominancia del enfoque normativo-reglamentario en la Administración de Empresas, que rutiniza y simplifica a través de leyes inmanentes desde hace décadas, y que ha sido soportado y exaltado por la corriente positivista de las llamadas Ciencias exactas.

Diversos autores (Luhmann, 2010; Mintzberg, 1976; Sartori \& Lara, 1984) realizan un abordaje problémico de los conflictos de interés que se presentan en la Organización con los stakeholders, y desarrollan un análisis de Poder y política, relacionado con la toma e influencia en las decisiones para el Desarrollo Organizacional. El problema del Poder y las decisiones, se configura como uno de los más complejos fenómenos a gestionar al interior de las Empresas.

El empirismo presente en el mundo empresarial representa un paradigma no resuelto dado que goza de algunas prácticas administrativas que pueden considerarse altamente efectivas dados los resultados en crecimiento y sostenibilidad que dichas empresas presentan, lo cual desarma el discurso construido desde las disciplinas de la gestión y la administración que tratan de justificar su existencia en escenarios académicos y empresariales, pero que ven afectada su credibilidad dada la elevada variabilidad en sus resultados frente a lo que el mundo empírico presenta.

La administración se manifiesta en variedad de formas y tipos, y por ello el mundo académico infiere que no hay consistencia propia. Esta balcanización de la práctica administrativa ha desdibujado la posibilidad de encontrar los aspectos comunes y mostrar con rigor las causas sistemáticas de la variación

\section{MODELOS Y METODOLOGÍAS DE GESTIÓN MODERNAS}

\subsection{Raíces históricas}

La Administración como disciplina, tiene sus orígenes "científicos" en el ámbito de la Industria, 
LÍNEA DE INVESTIGACIÓN: COMPETITIVIDAD DE EMPRESAS CONSTRUCTORAS

y como es frecuente en períodos tempranos de algunos campos de conocimiento, sus primeros aportes, fueron brindados por consultores, empresarios o ejecutivos entusiastas que se encontraban inmersos en escenarios de trabajo que demandaban soluciones que las fuentes teóricas no podían brindar.

Después del valioso aporte de (F. W. Taylor \& Fayol, 1977) con su incipiente pero fundamental concepto de medición del trabajo, tal Vez el académico más famoso que realizó los primeros aportes a la administración, fue Elton Mayo (1933) con su teoría motivacional y el enfoque de trabajo en equipo, seguido por Kurt Lewin (1935) con sus grupos T y la Teoría del Cambio, que brindó un impulso significativo a las nociones de eficiencia y eficacia Organizacionales, al entender que la transformación es un elemento determinante para la evolución o crecimiento sostenido.

De allí en adelante, se empezaron a producir sendos aportes a la Teoría administrativa Mary Parker Follet (1941) con el concepto de administración dinámica que se centra en la integración y en la responsabilidad compartida, lo cual dio cabida al empoderamiento, y cerro la distancia entre el enfoque rígido de la productividad y el enfoque humanista que estaba adquiriendo mayor relevancia en ese momento, Max Weber (1947) que caracteriza su modelo burocrático e identifica diferentes estilos de liderazgo presentes en éste, Abraham Maslow (1987) que propone la jerarquía de necesidades por medio de la articulación de los niveles de participación en la empresa al proceso de retribución biológicoemocional que la persona espera, Peter Drucker (1973) que dentro de sus innumerables aportes, y siendo el padre del Management, es reconocido por proponer la gestión por objetivos, y la gestión del conocimiento como elemento determinante de generación de valor en las décadas posteriores.

Chris Argyris por su parte (Argyris, 1957; Argyris \& Schön, 1978) realiza un aporte a la gestión con el aprendizaje organizacional como herramienta de evolución con sus ciclos de aprendizaje simple y doble, Frederick Herzberg (et al, 1959) continua aportando al concepto de higiene y motivación en el trabajo con diferentes factores, y Douglas Mc Gregor (1960) continua humanizando la empresa con su Teoría X y Y.

Alfred Chandler (1962) articula la Teoría estratégica y el desarrollo de la estructura organizacional con su concepto de Firma multidivisional.

Ted Levitt, (1962) se centra en el desarrollo del marketing y la globalización, haciendo énfasis en el enfoque de management impulsado por Drucker por casi una década.

Laurence J. Peter (1969) acuña el principio de Peter como síntoma de una mala gestión de carrera pero significativamente frecuente en el ámbito empresarial.

Charles Handy (1976) analizando la fenomenología de las organizaciones, propone su modelo de estructura tipo trébol, que gracias a su enfoque humanista, logró permear significativamente el cambio como estrategia de desarrollo Empresarial.

Elliott Jaques (1976) desarrolla la noción de sistemas sociales como defensa contra la ansiedad inconsciente. Identifica una relación entre la tarea organizacional y la dinámica inconsciente de grupo. Así mismo desarrolla el concepto de "tiempo de discreción" como variable para las estructuras salariales.

Alvin Toffler (1980) identifica y desarrolla el concepto de adhocracia como forma organizacional que evolucionará y reemplazará a la burocracia, dadas las exigencias innovadoras que tendrán las empresas en el futuro cercano. Centra su preocupación en la exclusión de algunos grupos etarios dado el afán desmedido por incrementar el nivel de apropiación tecnológico de las empresas, el cual dice el autor va a crear un shock debido al exceso de cambio en periodos muy cortos. 
Rosabeth Moss Kanter (1983) desarrolla el empoderamiento y analiza las fases posteriores al emprendimiento como estadio natural de las empresas. Considera que la administración debe ser abierta a un rango mayor de colaboradores que representen a todos los grupos sociales.

Geert Hofstede (1984) desarrolla la gestión cultural como elemento determinante en la comunicación efectiva empresarial, y propone 5 dimensiones para identificar patrones culturales de cada grupo.

Igor Ansoff (1984) es considerado el padre de la gestión estratégica y precursor del pensamiento estratégico en los negocios, desarrolló la matriz de expansión producto - mercado que postula que una empresa tiene un número limitado de opciones para el crecimiento: 1) "penetrar" el mercado con los productos ya disponibles, 2) desarrollar nuevos mercados con los productos ya disponibles, 3) desarrollar nuevos productos para los mercados ya disponibles, 0 , penetrar nuevos mercados con nuevos productos.

John Naisbitt (1984) es uno de los futurólogos más renombrados de las últimas décadas, y discute acerca de los desarrollos más importantes de los negocios, la política y la sociedad para los próximos años.

Edgar H. Schein (1985) ha realizado significativos aportes al desarrollo organizacional en áreas como el desarrollo de carrera, procesos de grupos, y cultura organizacional. El modelo propuesto por Schein incluye artefactos o comportamientos, valores defendidos o establecidos del comportamiento organizacional y supuestos básicos compartidos que están profundamente arraigados y que usualmente son inconscientes e irreconocibles pero que constituyen la esencia de la cultura.Michael Porter (1985) Es el padre de la estrategia competitiva, identificó cinco grandes categorías de presión en los entornos de competencia empresarial o nacional que definen aún las pautas de negociación vigentes en escenarios altamente competidos.
Warren Bennis (Bennis \& Nanus, 1985) se centró en el estudio del liderazgo y su desarrollo como grupo de habilidades adquiribles y desarrollables. Defiende y desarrolla la Adhocracia como vacuna contra la burocracia organizacional.

Sumantra Ghoshal (Ghoshal \& Bartlett, 1997) realizó significativos aportes a la gestión empresarial en relación con la Globalización y la Estructura Corporativa. Trabajó particularmente las estructuras matriciales en organizaciones multinacionales, y el conflicto y la confusión creada lo largo de las líneas geográficas y funcionales creadas. Sus últimos trabajos iban orientados a ponerle un alto a la economía como principal institución controladora de la Gestión organizacional

Peter Senge (1990) siendo ingeniero aeroespacial, se desenvuelve en el ámbito del desarrollo organizacional, y establece a lo largo del desarrollo de su teoría que el aprendizaje organizacional es la mejor herramienta que se tiene hoy en día en las empresas para enfrentar la dinámica cambiante del entorno, dado que éste entiende a las organizaciones como sistemas dinámicos.

Richard Pascale (1990) desarrolló el Marco de las 7's (style, staff, system, strategy, structure, skills and shared values), como modelo de transformación corporativa, en donde el centro de dicho proceso, radica en los valores compartidos.

Henry Mintzberg (Mintzberg \& Quinn, 1991) es tal vez el más importante pensador estratégico contemporáneo, dado que el, junto con sus colaboradores, se centraron en el análisis epistemológico de la Estrategia y en la compilación del pensamiento estratégico, elevando a ésta última al estatus de ciencia-arte. Trabajó significativamente acerca de los Roles del Manager, y la Educación en Management a nivel académico.

Fons Trompenaars (Trompenaars \& Hampden-Turner, 1994) se ha centrado en comunicación intercultural para la gestión de la 
LÍNEA DE INVESTIGACIÓN: COMPETITIVIDAD DE EMPRESAS CONSTRUCTORAS

Globalización y en la construcción de competencias transculturales. Su modelo cultural cuenta con siete dimensiones

- Universalismo vs particularismo

- El individualismo vs colectivismo

- Neutral vs emocional

- Específico frente a difusa

- Logro vs adscripción

- Secuencial vs sincrónica

- Interior moderación vs control externo

Gary Hamel (Hamel \& Prahalad, 1994) realizó significativos aportes al pensamiento estratégico con el concepto de Intención Estratégica o intento estratégico, desarrolló el concepto de Competencias básicas como habilidades desarrolladas según las estructuras mentales que permiten interactuar adecuadamente en entornos sociales y como habilidades necesarias para la resolución de problemas, desarrolló también el concepto de Arquitectura Estratégica como un conjunto de propósitos capacidades y relaciones.

Philip Kotler (1997) es considerado el líder del pensamiento de marketing, dado que ha dado reconocimiento al Marketing como Función Central de los Negocios, y ha impulsado la segmentación total, el poder que tiene el consumidor, la importancia de una propuesta de valor clara, la distribución como elemento estratégico, la co-creación con el cliente para generar dicho valor, la importancia de las métricas y de la medición del retorno de la inversión entre otras.

De esta breve caracterización se lograron identificar las siguientes áreas de interés como elemento determinante de la Gestión Organizacional, y que han sido objeto de avance académico significativo
- Estructura / División / Organización del trabajo

- Caracterización y estandarización de procesos, productos y servicios

- Enfoque al cliente interno y externo

- Sistemas de motivación, recompensa, involucramiento, empoderamiento y capacitación

- Participación y reconocimiento de los Stakeholders

- Construcción de valor para los Stakeholders

- Análisis interno y externo de corto y largo plazo para toma de decisiones

- Estrategia, alineación, agilidad

- Análisis sistémico-complejo

- Innovación, diseño y desarrollo de productos/servicios en ciclos cortos

- Rediseño y reingeniería de procesos / sistemas de calidad

- Desarrollo y apropiación tecnológica

- Bienestar sub-sistémico y supra-sistémico

- Gestión y análisis de la información y de la tecnología

- Énfasis en la medición y mejora en tiempo real

Estas áreas de interés, han marcado unas líneas muy definidas de desarrollo teórico-empírico, que han venido siendo incorporadas o implementadas en diversos Sectores o Regiones, y por tanto, han brindado una ventaja diferencial en los actuales escenarios globales de competitividad. 


\subsection{Tendencias principales}

Una vez realizado el análisis de las áreas de interés académico de la Administración y la Gestión, se identificaron nueve (9) tendencias evolutivas enmarcadas en este campo de conocimiento, las cuales se van a mencionar brevemente:

DESARROLLO CLIENTE: Desde el momento en el que C.K. Prahalad y Gary Hamel defienden la tesis de "el cliente como tomador de decisiones en la estrategia Corporativa", se sientan las bases para entender que éste, también se desarrolla como un actor más en la arquitectura del negocio, y que cada vez más adquiriere el poder sobre gran parte de las decisiones de innovación de producto/servicio que se presentan en la empresa.

Autores como (Blank, 2007) y (Cooper \& Vlaskovits, 2010) son pioneros en esta rama de la Gestión

CO-CREACION: De manera temprana, (J. A. Schumpeter, 2000) shumpeter, (Drucker, 1973) y (Peters \& Rodabaugh, 1988), identificaron que para sostener y elevar los niveles de competencia, se debía contar con la participación activa del cliente en la creación conjunta de la empresa, productos y/o servicios, y que dicha participación sólo rendiría frutos si se entendían de manera profunda los problemas que los clientes deseaban sortear.

La antorcha de la "creación conjunta" como decía Gary Hamel, fue fuertemente sostenida y desarrollada por (Blank, 2007), (Ries, 2011), Ash Maurya (Maurya, 2012) y Peter Fisk (Fisk, 2009) entre otros

LEAN THINKING: el pensamiento liviano ha producido varias raíces, que se originan en la manufactura liviana (referencia), y permearon otros campos del conocimiento como el pensamiento estratégico con las disciplinas del design Thinking (Kelley, Neck, O'Connor, \& ..., 2005) y visual thinking (Sibbet, 2008), la generación y escalonamiento de modelos de negocio con la metodología de Lean Startup, la gestión de proyectos con el modelo Lean Project (Ballard \& Howell, 2003), y la Experiencia de Usuario Liviana (Gothelf, 2013)

CAPACIDADES DINAMICAS/ESTRATEGIA CORPORATIVA: Schumpeter, (1934) considera que la innovación es casi la única habilidad que le permite a las Empresas competir en un mundo en el que variables como el diseño de productos, el incremento de eficiencia, y la calidad, definen las reglas del juego, y desencadenan lo que él llama "destrucción creativa". Y en este universo "Shumpeteriano", (Penrose, 1995; Teece, 2009; Williamson, 1975) sientan las bases teóricas de lo que son las capacidades dinámicas (Figura 1), que hacen referencia al potencial que tiene una organización para resolver sistemáticamente problemas, a través de una toma de decisiones oportuna, con miras al mercado, y con la intención de elevar su base de recursos.

Esta corriente de pensamiento, hace énfasis en tres categorías de capacidades o habilidades que la Empresa debe desarrollar. La primera es la capacidad de aprendizaje para la construcción de los denominados "activos estratégicos". La segunda categoría hace referencia a los nuevos activos que están relacionados con la capacidad de retroalimentación, la tecnología y la integración de clientes. Y la tercera categoría se refiere al proceso dinámico de transformación y reconfiguración de los activos ya existentes.

Esta Teoría, marcó una corriente de pensamiento estratégico de tipo Corporativo, en el que con un enfoque sistémico, y unas habilidades o dominios centrados en la adaptabilidad, tratan de definir y gestionar lo que ellos consideran, es el problema central en la formulación estratégica; La ruta estratégica de largo plazo. Dado que alguna modificación sobre ésta, se convierte en uno de los mayores problemas a los que la empresa se debe enfrentar.

Diversos autores, han nutrido esta corriente, que ha sido corroborada como camino de desarrollo en casi cualquier entorno o sector de la economía en la que se deban tomar decisiones estratégicas de largo aliento. 
LÍNEA DE INVESTIGACIÓN: COMPETITIVIDAD DE EMPRESAS CONSTRUCTORAS

Figura 1: Modelo de Capacidades Dinámicas. Fuente (Teece, 2009)
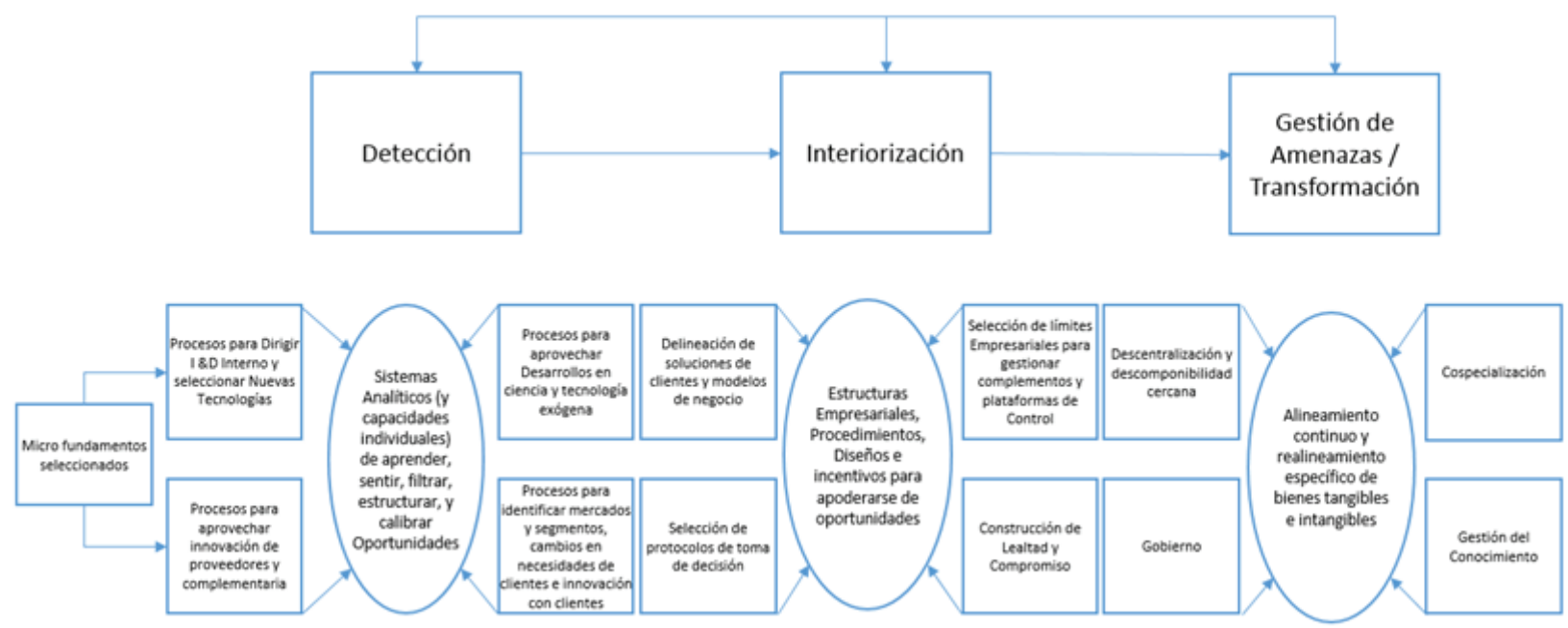

Fuente: elaboración propia

GESTION Y MODELAMIENTO DE PROCESOS DE NEGOCIO (BPM) / (BPMN): Con una herencia temprana en la Gestión por Procesos, y con el kit de herramientas que brindó el "Descubrimiento de Procesos de Negocio" (BPD), la Gestión y el Modelamiento de Procesos se entienden como un modelo analítico-visual de los procesos de una organización (Figura 2).Ello le permite verse hoy en día como un componente crítico de éxito en la Gestión Organizacional, dado que es usado para caracterizar mapas, crear líneas base de mejoramiento de procesos, diseñar procesos futuros con dichas mejoras incorporadas, brindar la capacidad de entender sus procesos internos en una connotación gráfica, y la posibilidad de comunicar a la organización dichos procesos de una manera estandarizada.

RESPONSABILIDAD SOCIAL EMPRESARIAL Y AMBIENTAL (RSEA): Desde la década del 50, diversos autores basados en los principios filosóficos de Milton Friedman, identificaron que la contribución económica de la empresa a la sociedad podía ser tal vez la función más importante de las Organizaciones en el sistema económico-social de los países con libertad de mercados.
A partir de este momento, autores como (Bowen, 2013; Carroll, 1991; David, 1949; Dempsey, 1958; Frederick, 1988; Heald, 1970), moldearon esta disciplina que en la actualidad, centra su desarrollo Teórico-práctico en cinco niveles: El cumplimiento del régimen legal, el desarrollo de la persona, la proyección familiar, la proyección de la comunidad y el diseño y ejecución de políticas de Estado.

GOBIERNO CORPORATIVO: Jensen y Meckling (1976) en su desarrollo sobre la Teoría de la Firma, abordan una problemática central en las Organizaciones relacionada con los conflictos de poder y de intereses entre el "principal" y el "Agente", y dada la relevancia del sector privado en el Desarrollo Económico Global, múltiples reformas orientadas al mercado generadas en gran cantidad de países, elevaron y definieron con mayor especificidad los estándares de lo que hoy se entiende como Buen Gobierno o Gobierno Corporativo, trayendo grandes beneficios relacionados con la reducción de costos de capital, y acceso, atracción de recursos Internacionales, mejor distribución del riesgo entre actores, aumento de eficiencia operacional y crecimiento económico entre otros. 
Figura 2: Modelo Business Process Management. Fuente: (Lusk, Paley, \& Spanyi, 2005)

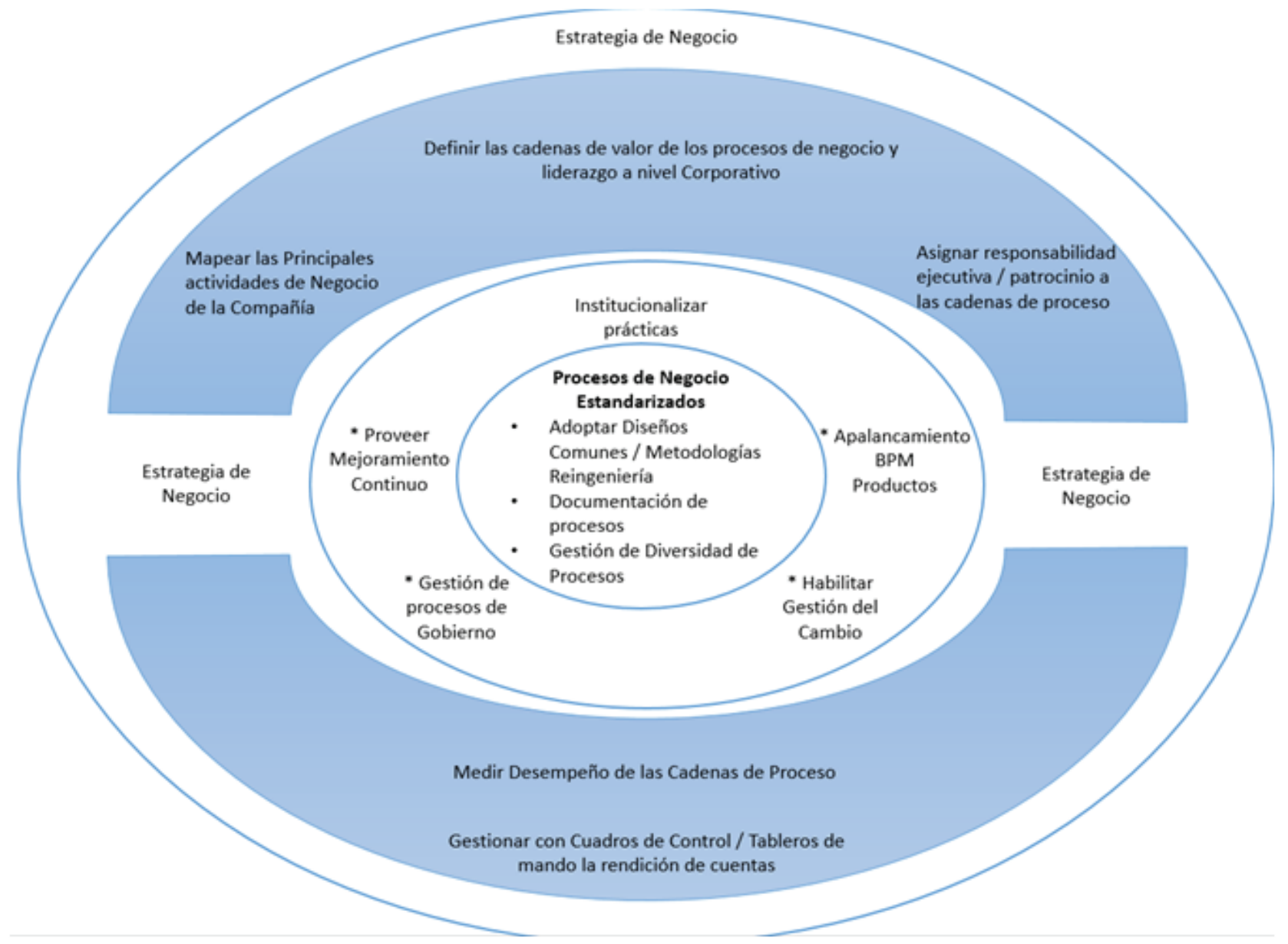

Fuente: elaboración propia

Las dos más comunes aproximaciones están relacionadas con brindar al inversionista algún tipo de poder. El primero relacionado con el poder legal para evitar la expropiación por parte del Manager, el segundo relacionado con los significativos derechos de control que deberían tener los inversionistas mayoritarios, siendo la combinación de éstas dos aproximaciones, uno de los principales objetos de debate sin solución de la actualidad.

Si se quisiera sintetizar de manera muy general, los modelos de Gobierno Corporativo, van orientados a mediar entre las partes para mutuo beneficio, y con este principio fundamental, construyen las políticas y lineamientos específicos de funcionamiento (Figura 3).
Figura 3: Modelo General Gobierno Corporativo.

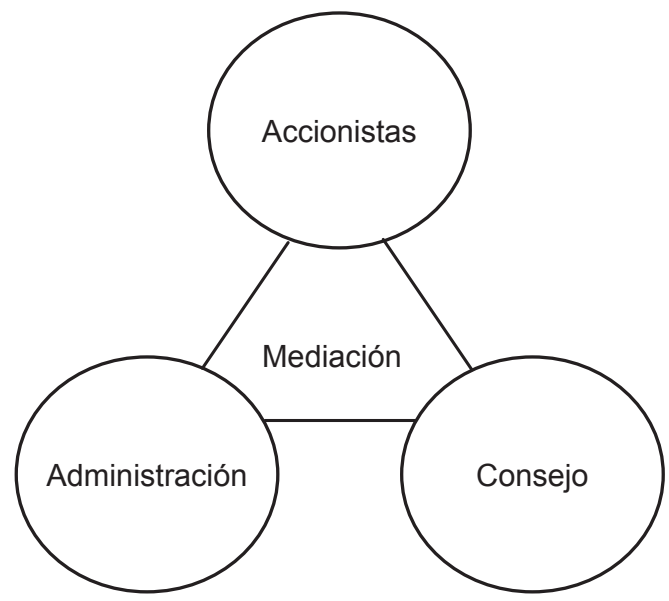

Fuente: (Jensen \& Meckling, 1976) 
LÍNEA DE INVESTIGACIÓN: COMPETITIVIDAD DE EMPRESAS CONSTRUCTORAS

ANÁLISIS DE ENTORNO / PROSPECTIVA I FUTUROLOGÍA: Tal vez la primera referencia que aparece en la literatura relacionada con análisis del entorno, se encuentra en el libro titulado Business Policy (Christensen, Andrews, Bower, Hamermesh, \& Porter, 1965), con la propuesta de la Matriz DOFA en donde se abordan factores externos a ser analizados para el correcto desarrollo e implantación de la estrategia Corporativa. Desde este momento, sendos autores, comenzaron a trabajar sobre esta corriente, con miras a un desarrollo estratégico cada vez más asertivo.

Hoy en día, esta disciplina ha evolucionado hacia conceptos de análisis de largo plazo para la implantación de estrategias en las que se simulan diferentes escenarios futuros posibles 0 "futuribles" en donde la combinación de variables endógenas con factores exógenos, buscan la fórmula perfecta que permita el posicionamiento y crecimiento Empresarial en cada escenario en particular (Figura 4). Dicho enfoque ha dado cabida a disciplinas como la Prospectiva y la Futurología que buscan el entendimiento de las realidades futuras en las que las empresas actuales deberán competir.

INNOVACION Y CREATIVIDAD EMPRESARIAL: De acuerdo con el manual de OSLO (OECD \& Eurostat, 2005), la Innovación es "la introducción de una nuevo o significativamente mejorado, producto (bien o servicio), de un proceso, de un nuevo método de comercialización o de un nuevo método organizativo, en las prácticas internas de la empresa, la organización del lugar de trabajo o las relaciones exteriores".

Los orígenes tempranos del concepto los podemos observar en la sociología con los aportes de (Hart, 1931) y lo secundaron (GilfiIlan, 1970; Ogburn, 1937) También sociólogos. Joseph Schumpeter, (1934) se une a la discusión en 1932 y 1934 con el concepto de "destrucción creativa"

Robert Sternberg (Sternberg, 2007; STERNBERG, PRETZ, \& KAUFMAN, 2003), sienta uno de los primeros debates acerca de las formas de innovación actuales proponiendo ocho tipos: Por Réplica, Por Redefinición, Por Innovación incremental hacia adelante, por avance de incremento hacia adelante, por Re-direccionamiento, por reconstrucción, por reiniciación, y por integración.

Figura 4. Análisis de Entorno.

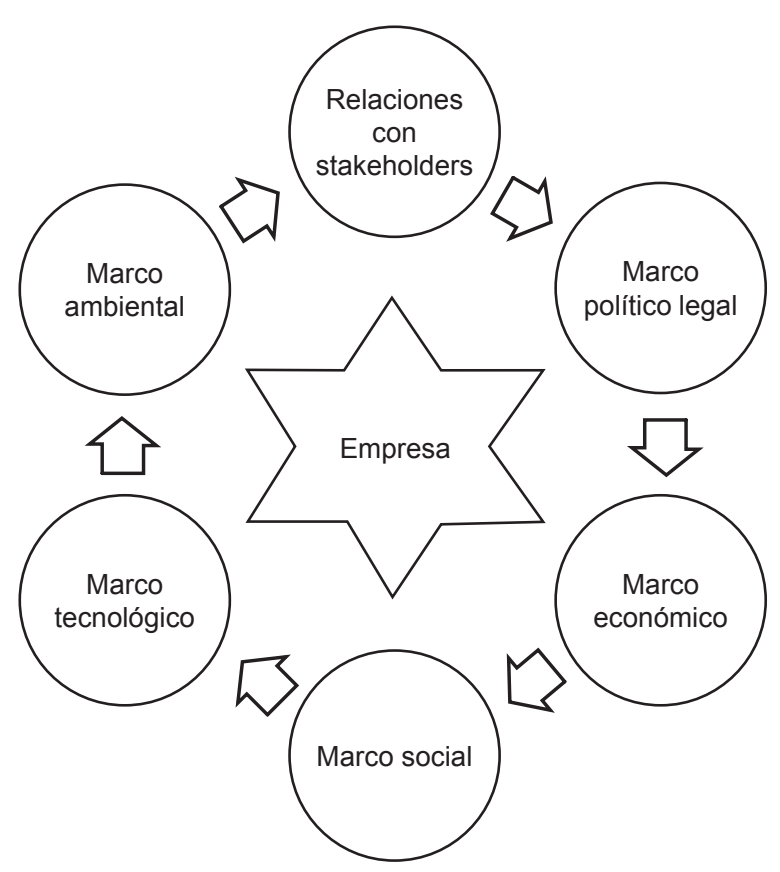

Fuente: Elaboración Propia

Estos referentes académicos realizaron importantes aportes a la construcción de modelos Nacionales de desarrollo innovador, que tuvieron que ser bajados del nivel Macro, al nivel de las compañías, y una vez allí, aparecen nuevos enfoques teórico-prácticos como la innovación disruptiva o la Teoría de cadena de valor de Porter (1987), el modelo de innovación estratégica de procesos de (Afuah, 2003; Allan \& Christopher, 2001) (Figura 5). El modelo de ciclo de vida de madurez de 15 categorías de Geoffrey Moore (2005) (Figura 6), Y el modelo de innovación estratégica de Negocios de Gary Hamel (2002) (Figura 7), que dieron cabida a metodologías ya mencionadas como el Design Thinking, el Lean Thinking, los Modelos de Negocio, así como múltiples prácticas y herramientas de Creatividad Empresarial. 
Figura 5. Modelo de Innovación Estratégica de Procesos.

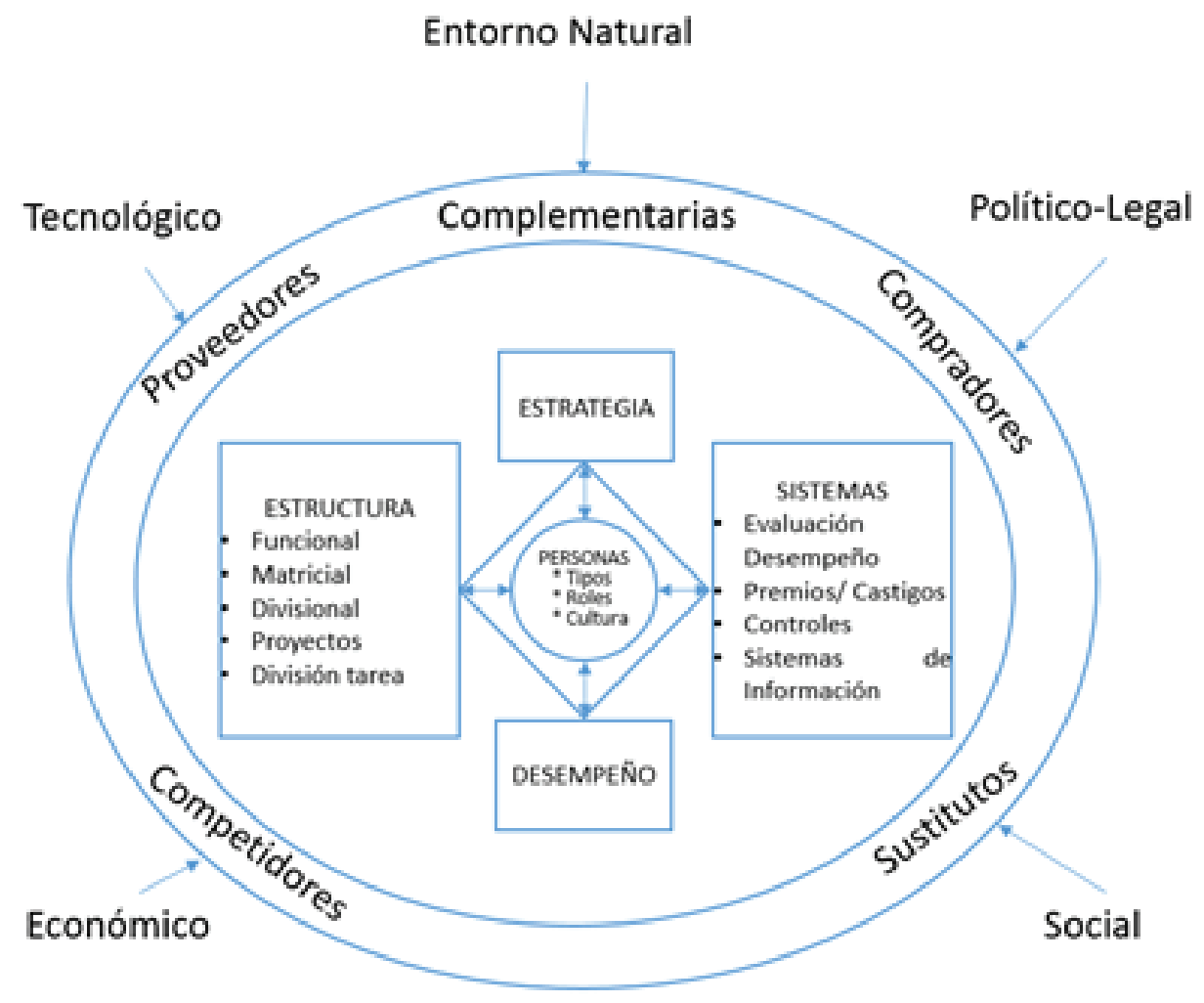

Fuente: (Afuah, 2003; Allan \& Christopher, 2001)

Figura 6. Modelo de ciclo de vida de madurez de 15 categorías.

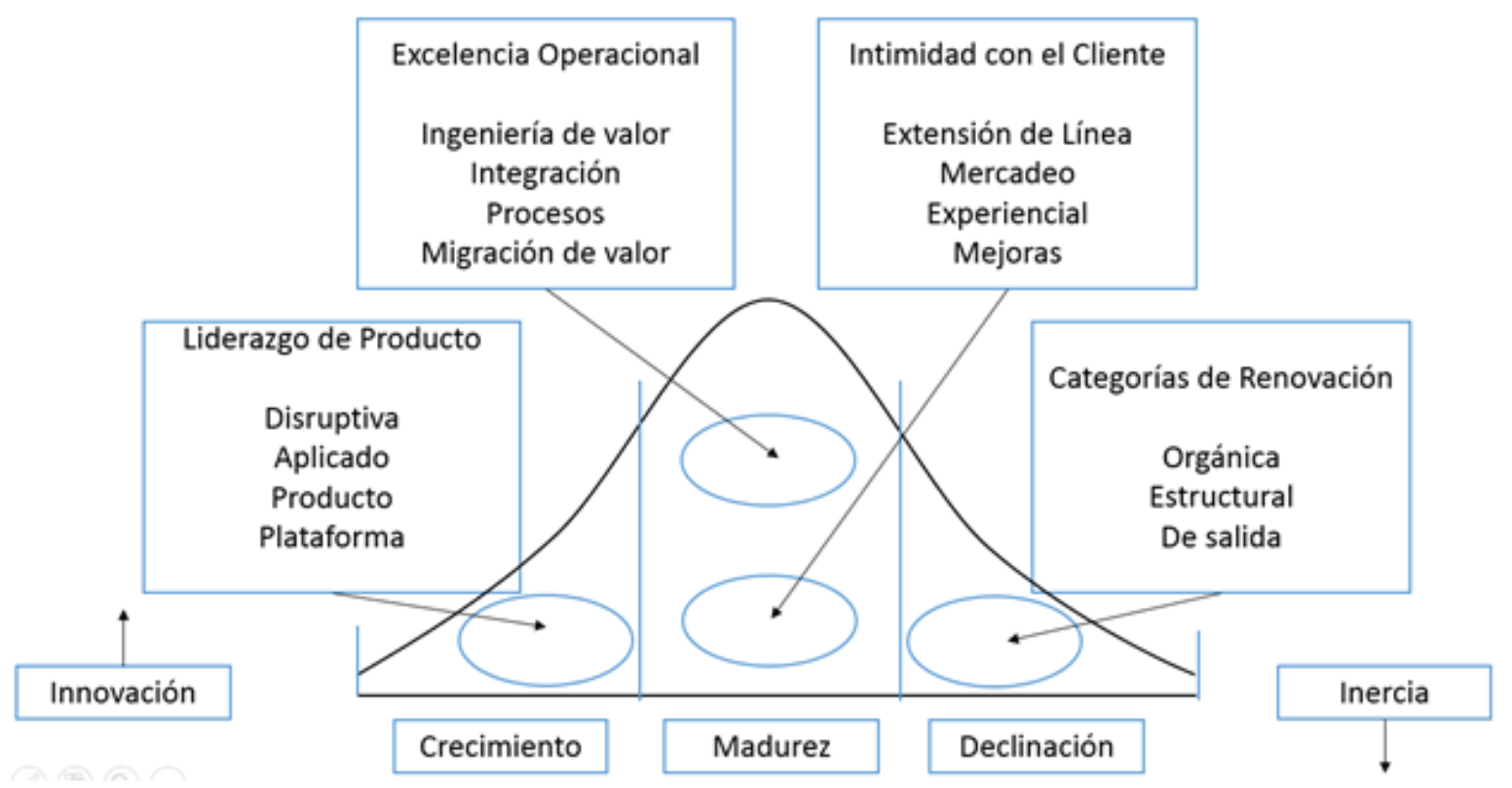

Fuente: (Moore, 2005) 
LÍNEA DE INVESTIGACIÓN: COMPETITIVIDAD DE EMPRESAS CONSTRUCTORAS

Figura 7. Modelo de Innovación Estratégica de Negocios.

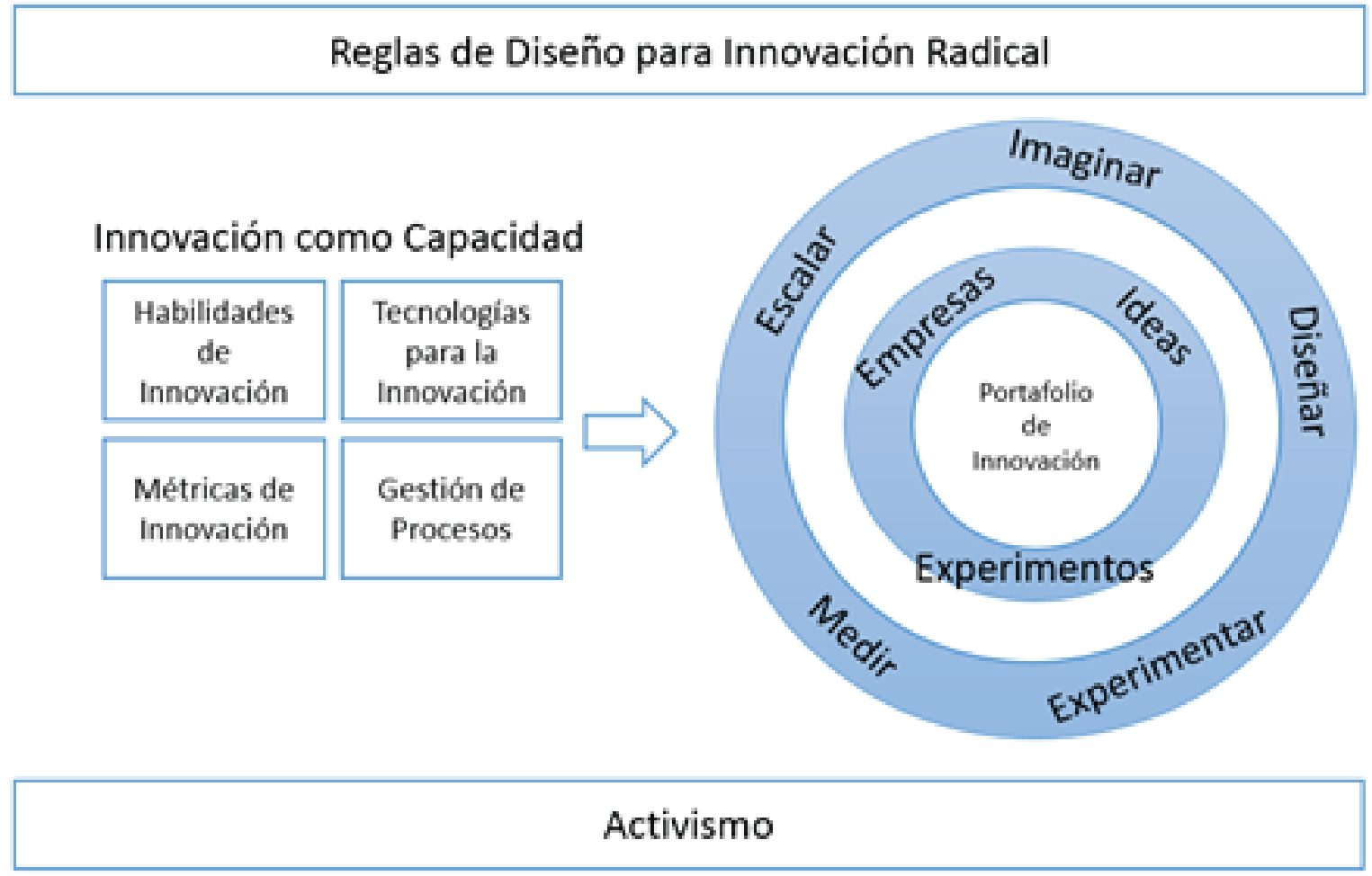

Fuente: (Hamel, 2002)

\subsection{Modelos y metodologías modernas de mayor impacto identificadas}

MODELOS NEGOCIO: los Modelos de Negocio, son metodologías que explican cómo las Organizaciones "desarrollan valor" a través de una arquitectura de Empresa que sea desarrollable y sostenible en entornos Globales altamente competitivos. (Osterwalder, Pigneur, \& Smith, 2005), proponen el análisis y desarrollo de nueve (9) dimensiones (Figura 8) en las que las organizaciones deben, centrar sus esfuerzos estratégicos para incrementar su competitividad, optimizar sus procesos y recursos, abarcar nuevos mercados con altos niveles de fidelización y retención, y crear y mantener relaciones estratégicas con aliados y proveedores, para garantizar la visibilidad en la construcción del valor, lo cual redunda en sostenibilidad.
De acuerdo con la literatura revisada, el diseño y desarrollo de Modelos de Negocio, se ha convertido hoy en día, en una de las principales y más nutridas tendencias teórico prácticas, y se ha convertido en pilar epistemológico de algunas corrientes que la precedieron

Figura 8. Modelo de Negocios.

\begin{tabular}{|c|c|c|c|c|}
\hline \multirow{2}{*}{$\begin{array}{c}\text { Red } \\
\text { Aliados }\end{array}$} & $\begin{array}{c}\text { Actividades } \\
\text { clave }\end{array}$ & \multirow{2}{*}{$\begin{array}{c}\text { Propuesta } \\
\text { de valor }\end{array}$} & $\begin{array}{c}\text { Relaciones } \\
\text { clientes }\end{array}$ & \multirow{2}{*}{ Segmentos } \\
& & \multicolumn{2}{|c|}{ Flujos de ingreso } \\
\hline \multicolumn{3}{|c|}{ Costos } & \\
\hline
\end{tabular}

Fuente: (Osterwalder et al., 2005)

LEAN STARTUP: La metodología de Lean Startup propuesta por Ries (2011) es el resultado de un proceso de experimentación personal de creación de empresas de base tecnológica que le llevo casi una década de aciertos y 
desaciertos en el mundo competido del Sillicon Valley (Figura 9). En este libro el autor propone una metodología de creación de startups basándose en los modelos lejanos de desarrollo como la innovación liviana (Sehested, 2011), el pensamiento liviano (Womack \& Jones, 2003), y manufactura liviana (Inc. S., 2004), y metodologías cercanas como desarrollo del cliente (S. G. Blank, 2007), modelos de negocio (Osterwalder, Pigneur, \& Smith, 2005) y co-creación (Read, Dew, Sarasvathy, Song, \& Wiltbank, 2009) (Fisk, 2011).

Esta metodología se basa en la construcción y validación de hipótesis entorno a posibles clientes y sus expectativas de nuevos productos y servicios. Y consiste de tres etapas en las que construye el modelo de negocio de la Startup, y se comienza a experimentar y a generar aprendizaje, se realizan mediciones profundas para determinar si se realiza un viraje importante en el modelo o si se continúa perseverando, para finalmente, escalar, adaptar e incorporar innovación.

El autor, expone la efectividad de la metodología, no solamente por las experiencias propias, sino por un gran volumen de evidencia empírica recolectada de startups que aplicaron éste método con buenos resultados en escenarios de elevada incertidumbre.

PENSAMIENTO DE DISEÑO: EI Pensamiento de Diseño de David Kelley (Kelley et al., 2005) es una metodología centrada en el análisis del cliente, que utiliza las fases de creatividad divergente y convergente para resolver problemas que ya no solamente se refieren a situaciones de diseño de productos y servicios, sino también al ámbito de la estrategia y del Modelo de Negocios. Esta Metodología, tiene una secuencia lógica de pasos que en su primera fase de divergencia, se plantea preguntas, observa e identifica problemas, y una vez encontrada la inspiración, se sintetizan los hallazgos, se evalúa, desarrolla, prueba y ejecuta una solución definitiva a través de la fase convergente.
Figura 9. Modelo lean Startup.

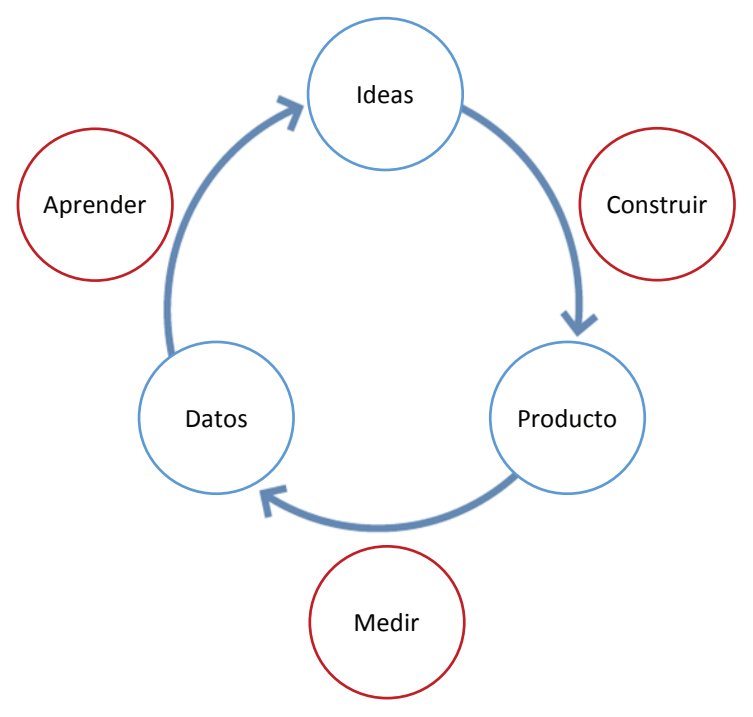

Fuente: (Ries, 2011)

DESARROLLO DE CLIENTES: La metodología de Desarrollo de Clientes propuesta por Steve Blank (Blank, 2007), se centra en el descubrimiento del mercado, a través del establecimiento de los atributos que el producto debe tener para resolver las necesidades específicas que el cliente tiene, y a partir de éste descubrimiento, gestiona los recursos adecuados para escalar el Modelo de Negocios

ARQUITECTURA DE EMPRESA: Paul Bodine (Bodine \& Hilty, 2009) desarrolló esta práctica, y se ha posicionado como una importante actividad empresarial que involucra a profesionales de todas las áreas y que busca la transformación de la estrategia corporativa en "diseños de negocios" que incrementen la participación en el mercado, los márgenes de rentabilidad y la flexibilidad, mientras se reduce el riesgo.

Ésta actividad, incluye habilidades para el diseño dinámico y flexible de nuevos modelos de negocio adaptables a los actuales entornos competitivos; la incorporación de la voz del cliente, empleados expertos y gerentes para garantizar necesidades cubiertas; el desarrollo de soluciones coordinadas para eliminar conflictos; de- 
LÍNEA DE INVESTIGACIÓN: COMPETITIVIDAD DE EMPRESAS CONSTRUCTORAS

finición de métricas que provean la información tación estrictamente necesaria en los términos necesaria para el mejoramiento de la toma de que cada audiencia entienda e incorpore. decisiones futura; y la generación de documen-

Figura 10. Modelo Pensamiento de Diseño.

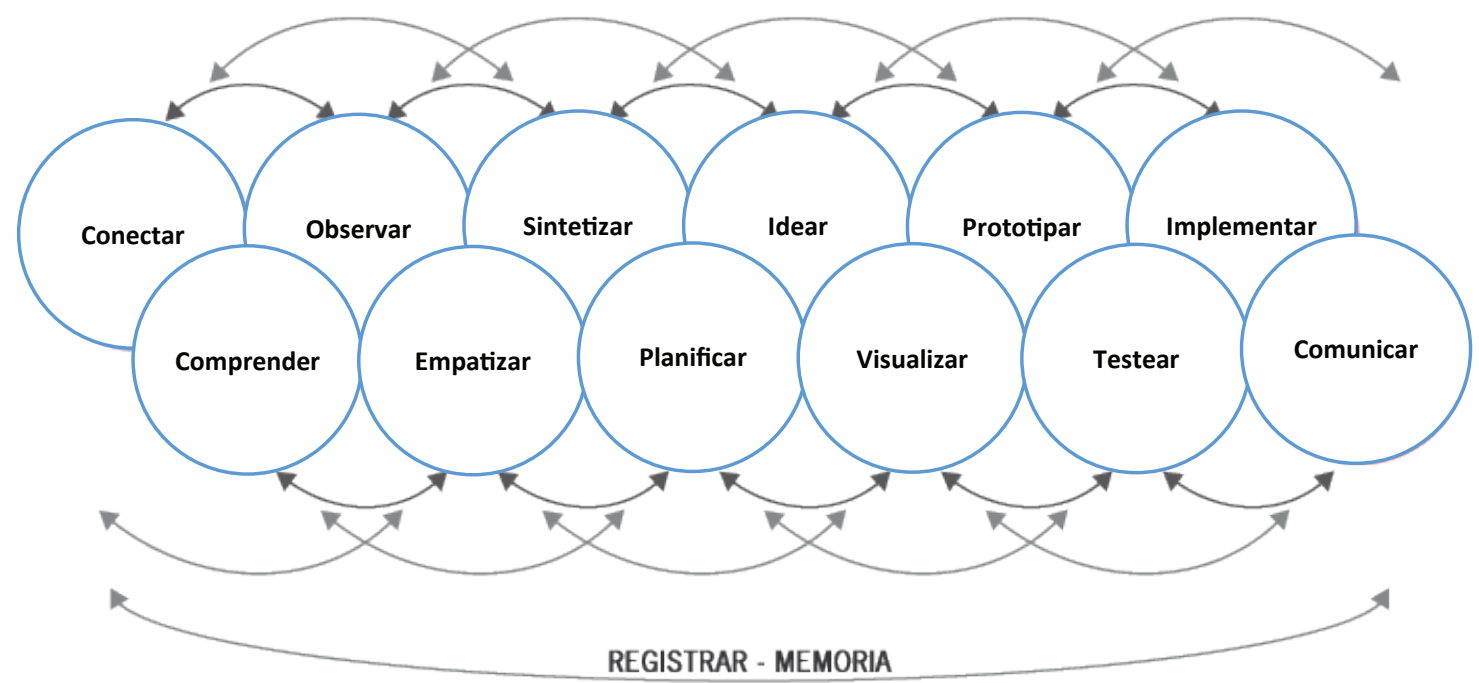

Fuente: (Kelley et al., 2005)

Figura 11. Modelo Desarrollo del Cliente.

\section{Startup}

Busca

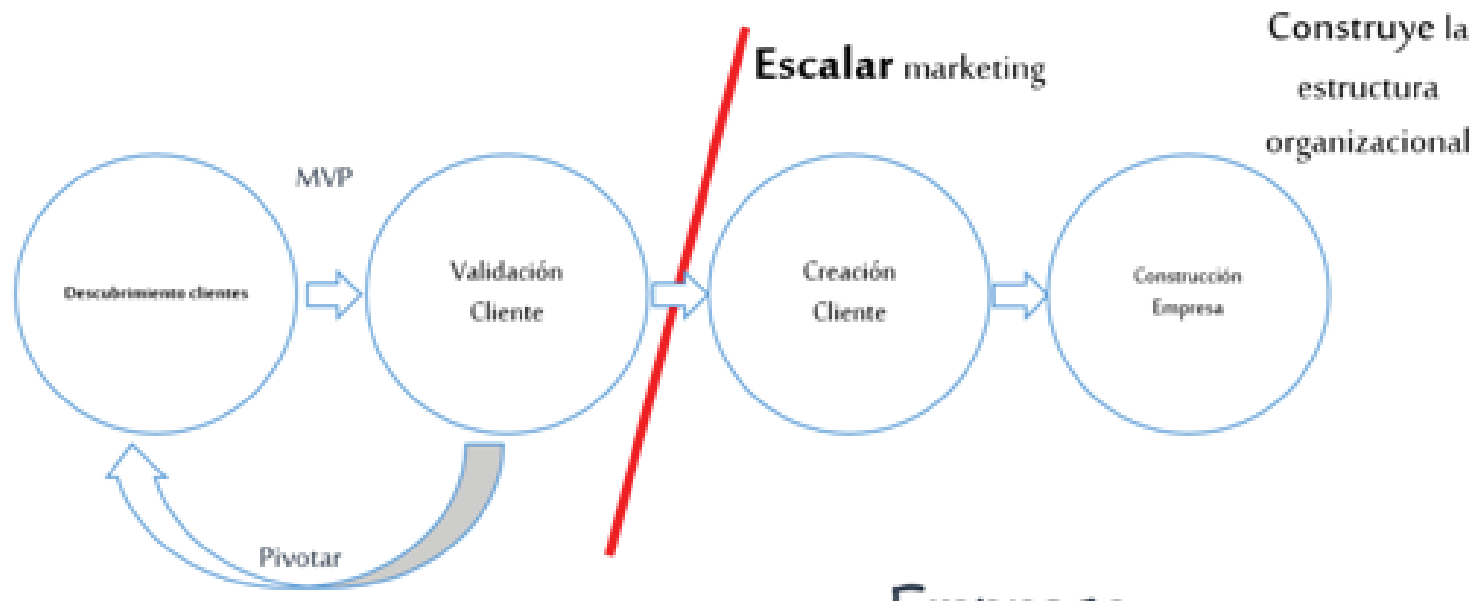

Empresa

Ejecuta

Fuente: (Blank, 2007) 
Figura 12. Modelo Arquitectura de Negocios.

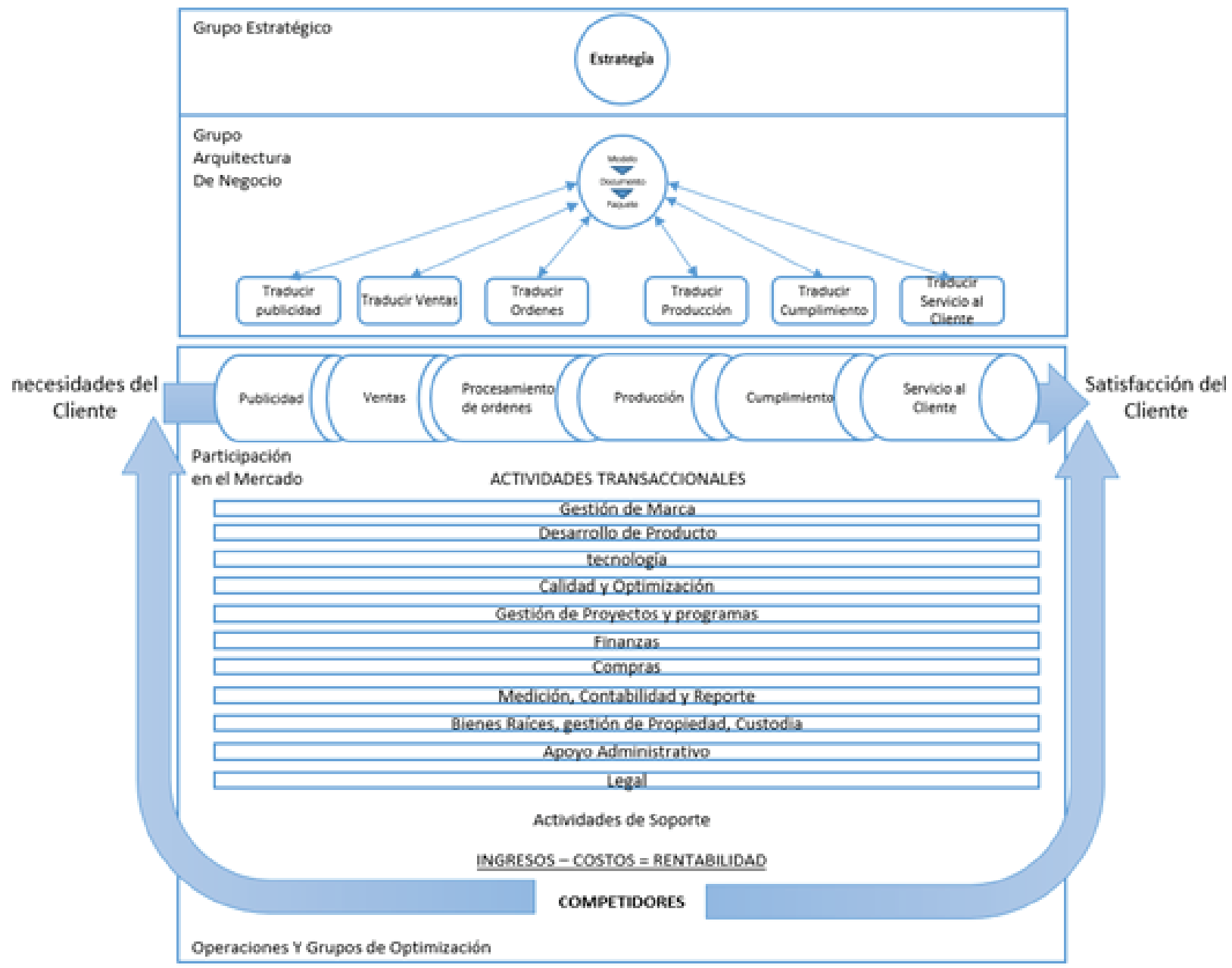

Fuente: Business Architecture: An Emerging Profession. Paul Arthur Bodine and Jack Hilty April 28, 2009; earlier editions (C) 2008. P.7

TABLEAU DE BORD / BALANCED SCORECARD: El tablero de mando Francés tiene sus orígenes hace más de 40 años, como una herramienta de control gubernamental, e impulsada posteriormente por la industria francesa. Luego de múltiples aportes (de Guerny, Guiriec, \& Lavergne, 1990), se consolida como una práctica ampliamente aceptada principalmente en Europa, en donde a través de una metodología de "anidación de objetivos" se articulan horizontal y verticalmente las metas locales con metas superiores en tableros específicos de gestión. Estos tableros, separan los contenidos de las unidades de gestión en tres diferentes clusters de informa- ción (Coordinación, control, y resultados) para los diferentes niveles, y aunque según críticos académicos, presente algunos defectos como; La poca atención que le presta al desglose corporativo, generando una ausencia de enfoque compartido y cooperación, Exceso de indicadores, muy orientados a la perspectiva interna y Predominio del control táctico-operativo a expensas de la perspectiva estratégica, es un modelo que ha demostrado su funcionalidad a través de múltiples casos empresariales y gubernamentales.

Por otro lado, el Balanced Scorecard, desarrollado por (Kaplan \& Norton, 1996), retoma 
LÍNEA DE INVESTIGACIÓN: COMPETITIVIDAD DE EMPRESAS CONSTRUCTORAS

Ios principales conceptos del Tablero de Mando Francés, y ajusta algunos conceptos al contexto occidental. Éste modelo, centra más sus esfuerzos en la gestión financiera dado su enfoque a la satisfacción de los accionistas, y volcando toda la relación causal para este fin, articulando el servicio al cliente como elemento determinante para el desarrollo financiero, la gestión operacional después y finalmente las actividades de aprendizaje y gestión del conocimiento como punto de origen para desencadenar el proceso.

En cuanto a las diferencias con el Modelo Francés, en primer lugar, el BSC no hace una clara diferencia entre la Dimensión Política de la Empresa, la Dimensión Estratégica y la Dimensión económica (palancas y Resultados), no presenta un procedimiento estandarizado para el desglose de la misión, visión, valores. Se enfoca principalmente en los resultados financieros como ya se mencionó, asume una visión estática de la empresa y no propone un examen o modificación constante de sistema de los indicadores de control, como lo hace su homólogo.

Estudios posteriores (Daum, 2005), han intentado reconciliar el enfoque arriba-abajo orientado al accionista del modelo Americano, con el enfoque abajo-arriba orientado al desempeño operativo del modelo Francés con cierto nivel de éxito, pero aún siguen muy marcadas las diferencias

Figura 13: Modelo Balanced Scorecard.

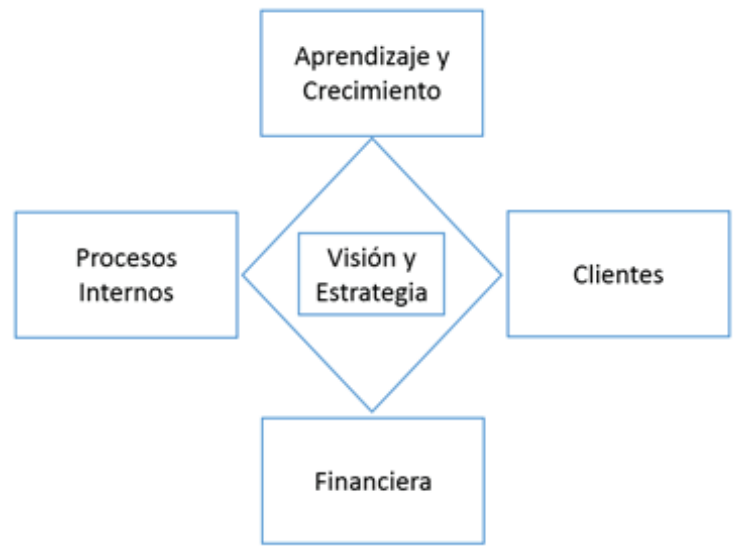

Fuente: (Kaplan \& Norton, 1996)

\section{PRÁCTICAS DE GESTIÓN IDENTIFICADAS EN LA GERENCIA DE EMPRESAS CONSTRUCTORAS}

\author{
ANÁLISIS DE LIBROS Y ARTÍCULOS:
}

Para este análisis, se realizó una revisión general de la producción académica de libros y artículos académicos que se encontraban a disposición en bases de datos indexadas a nivel Global. Y se encontraron 184 artículos o libros relacionados con Administración de Empresas Constructoras (Ver Anexo 1), de los cuales se identificaron 38 sub tópicos de conocimiento en los que se ha profundizado. Se puede Observar que las temáticas que más han sido investigadas son Riesgo, Seguridad Industrial, y bienestar, Presupuesto, Gestión Financiera, Logística y abastecimiento, y Presupuesto.

Temáticas Hallazgos

\begin{tabular}{|l|c|}
\hline Alianzas & 4 \\
\hline Alianzas, y socios & 4 \\
\hline Auto-empleo & 1 \\
\hline Calidad & 2 \\
\hline capacitación y Entrenamiento & 2 \\
\hline Constructibilidad & 3 \\
\hline Desarrollo Gerencial & 3 \\
\hline Educación & 1 \\
\hline Estrategias de Financiación & 6 \\
\hline Evidencia Empírica & 8 \\
\hline Gerencia de Empresas Constructoras & 2 \\
\hline Gestión cadena Abastecimiento & 10 \\
\hline Gestión de Operaciones & 1 \\
\hline Gestión de Proyectos & 3 \\
\hline Gestión de Sociedades & 7 \\
\hline Gestión del Conflicto & 2 \\
\hline Gestión del Conocimiento/aprendizaje & 2 \\
\hline Gestión del Entorno & 1 \\
\hline gestión del Riesgo & 1 \\
\hline Gestión del Talento Humano & 10 \\
\hline
\end{tabular}




\begin{tabular}{|l|c|}
\hline \multicolumn{1}{|c|}{ Temáticas } & Hallazgos \\
\hline Gestión del valor & 6 \\
\hline Gestión Financiera & 14 \\
\hline Innovación en Management & 1 \\
\hline Legal & 2 \\
\hline Mercadeo Empresas Constructoras & 1 \\
\hline Multiculturalidad & 3 \\
\hline organización del trabajo & 5 \\
\hline Plan de negocios & 1 \\
\hline Planeación Estratégica & 2 \\
\hline Presupuesto & 23 \\
\hline Referenciación Competitiva & 6 \\
\hline Regulaciones de seguridad y salud & 19 \\
\hline Re-ingeniería & 8 \\
\hline Relaciones Industriales & 5 \\
\hline Toma de decisiones Cuantitativa & 1 \\
\hline TQM & 8 \\
\hline Trabajo en Equipo & 6 \\
\hline Total general & 184 \\
\hline
\end{tabular}

\section{ANALISIS DE TESIS Y MONOGRAFÍAS:}

Para esta fase, se analizó el material producido por estudiantes de pregrado y posgrado pertenecientes a programas relacionados con la Administración y la Gerencia, y que tuviera injerencia directa sobre la administración de Empresas Constructoras.

Para ello, se incluyeron dentro de la búsqueda a cuatro (4) universidades que contaran con programas afines, y que tuvieran disponibilidad de acceso a la información.

Como resultado de dicha búsqueda, se identificaron 90 trabajos de tesis y monografías, que han sido llevados a cabo desde el año 1997.

Se puede observar en la siguiente tabla, la distribución de frecuencias con respecto a las áreas de interés

\begin{tabular}{|l|c|}
\hline \multicolumn{1}{|c|}{ Tema } & Cantidad \\
\hline Balanced Scorecard & 5 \\
\hline Benchmarketing & 1 \\
\hline Bpm & 3 \\
\hline Capacidades Dinamicas/Estrategia & 5 \\
\hline Coaching & 2 \\
\hline Enfoque Al Cliente & 1 \\
\hline Estructura Organizacional & 3 \\
\hline Evaluacion Desempeño & 2 \\
\hline Finanzas / Financiacion / Riesgo & 5 \\
\hline Formulacion/Viabilidad & 8 \\
\hline Gerencia Proyectos & 1 \\
\hline Gestion De Empresa & 11 \\
\hline Gestion Del Conocimiento & 1 \\
\hline Gestion Talento Humano & 4 \\
\hline Lean Construction & 1 \\
\hline Legal & 1 \\
\hline Mercadeo / Ventas & 4 \\
\hline Planeacion / Control & 7 \\
\hline Premiacion / Recompensa & 2 \\
\hline Principios Admin & 1 \\
\hline Productividad & 3 \\
\hline Rse & 4 \\
\hline Seguridad Industrial & 2 \\
\hline Sgc / Mejora Continua & 10 \\
\hline Tecnología & \\
\hline Tendencias/Prospectiva & \\
\hline Total general & \\
\hline
\end{tabular}

Al analizar la producción tanto de libros y artículos, como de Tesis, Monografías y trabajos de grado, se puede observar una predominancia productiva en las áreas de Finanzas, financiación y gestión del Riesgo del $17,7 \%$, seguido de Gestión del Talento Humano, Formación, Evaluación del desempeño, motivación, Coaching y Desarrollo profesional con un $11,6 \%$.

En la segunda categoría de producción, se encuentran la Seguridad Industrial con $7,6 \%$, Sistemas de Calidad y mejora continua con $7,2 \%$, Gerencia y Gestión de Empresas Constructoras con $6,1 \%$, y Productividad con $5,4 \%$. 
LÍNEA DE INVESTIGACIÓN: COMPETITIVIDAD DE EMPRESAS CONSTRUCTORAS

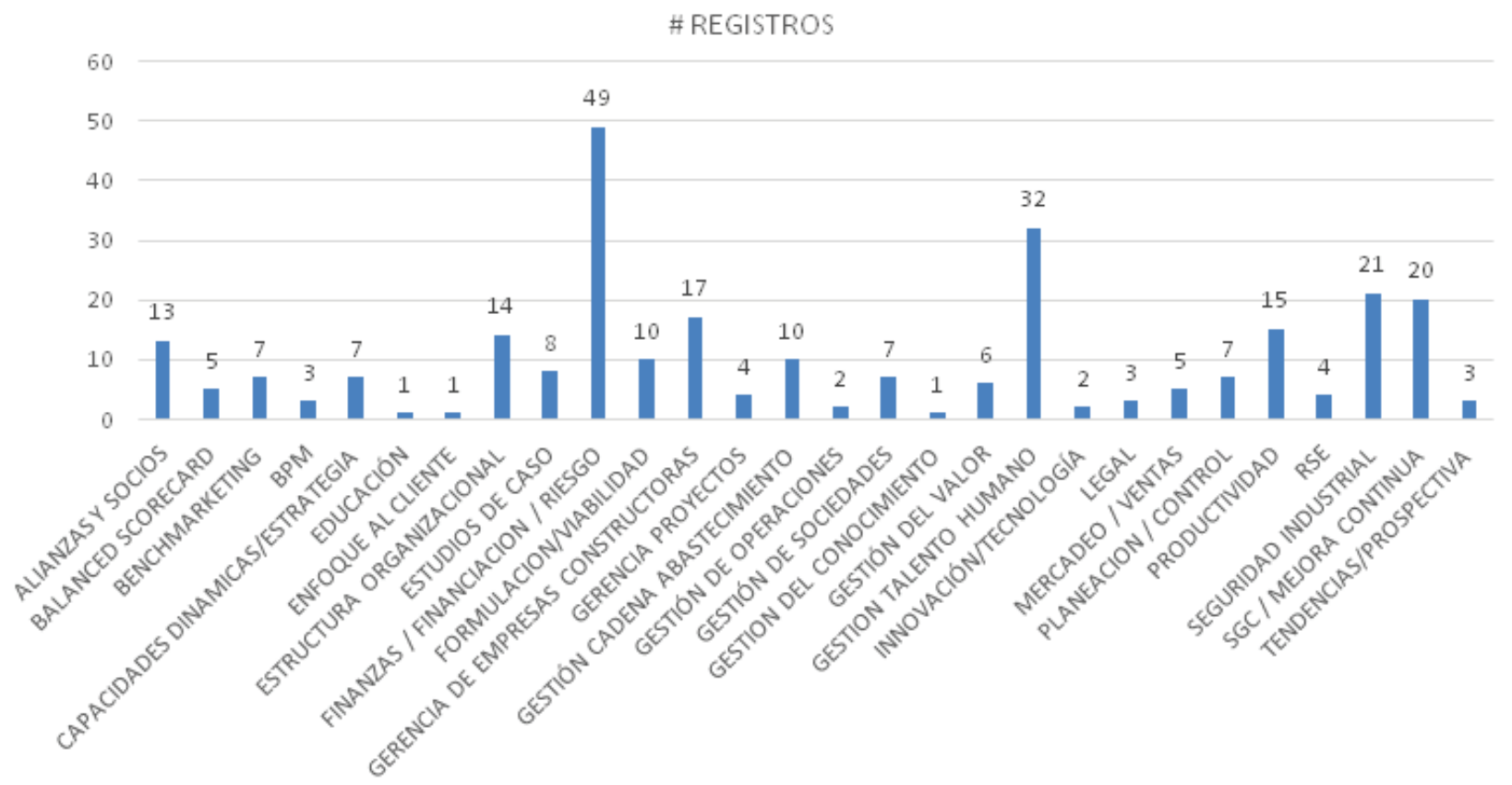

Fuente: Elaboración Propia

Una vez analizadas las temáticas de Administración y Gestión, se realizó una comparación para determinar cuáles de ellas, están siendo desarrolladas de manera Teórico-conceptual en el Sector de las Empresas Constructoras a nivel global, y se determinó que el $76,7 \%$ si han tenido algún tipo de aproximación, sin embargo, existen algunas temáticas que todavía no han permeado el ámbito de la Gerencia de Empresas Constructoras.

\begin{tabular}{|l|c|c|}
\hline \multicolumn{1}{|c|}{ Tematica } & $\begin{array}{c}\text { Temas } \\
\text { management }\end{array}$ & $\begin{array}{c}\text { Temas abordados } \\
\text { en construcción }\end{array}$ \\
\hline adhocracia, post-industrialización & $\mathrm{SI}$ & $\mathrm{SI}$ \\
\hline Administracion científica & $\mathrm{SI}$ & $\mathrm{SI}$ \\
\hline Análisis de entorno & $\mathrm{SI}$ & $\mathrm{SI}$ \\
\hline Anclas de carrera, cultura corporativa & $\mathrm{SI}$ & $\mathrm{SI}$ \\
\hline Aprendizaje organizacional, ciclo de aprendizaje simple y doble & $\mathrm{SI}$ & $\mathrm{SI}$ \\
\hline Arquitectura negocios & $\mathrm{SI}$ & $\mathrm{NO}$ \\
\hline Bpm & $\mathrm{SI}$ & $\mathrm{NO}$ \\
\hline Inteligencia de negocios & $\mathrm{SI}$ & $\mathrm{NO}$ \\
\hline Calidad & $\mathrm{SI}$ & $\mathrm{SI}$ \\
\hline Calidad 6 sigma iso & $\mathrm{SI}$ & $\mathrm{SI}$ \\
\hline Capacidades dinámicas & $\mathrm{SI}$ & $\mathrm{NO}$ \\
\hline Co-creación & $\mathrm{SI}$ & $\mathrm{NO}$ \\
\hline Desarrollo cliente & $\mathrm{SI}$ & $\mathrm{NO}$ \\
\hline
\end{tabular}




\begin{tabular}{|c|c|c|}
\hline Tematica & $\begin{array}{c}\text { Temas } \\
\text { management }\end{array}$ & $\begin{array}{l}\text { Temas abordados } \\
\text { en construcción }\end{array}$ \\
\hline Empoderamiento, la firma post-emprendedora & SI & SI \\
\hline Estrategia & SI & SI \\
\hline Factores de higiene y motivacionales & $\mathrm{SI}$ & SI \\
\hline Filosofía de la ciencia & $\mathrm{SI}$ & NO \\
\hline $\begin{array}{l}\text { Gestión cultural, } 5 \text { dimensiones para identificar patrones culturales } \\
\text { de cada grupo }\end{array}$ & SI & SI \\
\hline Gestión de la globalización, aspectos culturales & $\mathrm{SI}$ & SI \\
\hline Gestión estratégica, análisis de brecha, sinergia & SI & SI \\
\hline Gestión por objetivos, gestión del conocimiento & SI & SI \\
\hline Globalización y estructura corporativa & SI & SI \\
\hline Gobierno corporativo & SI & SI \\
\hline Grupos t, teoría del cambio & SI & SI \\
\hline Integración, compartir responsabilidad & SI & SI \\
\hline Jerarquía de necesidades & SI & SI \\
\hline La organización que aprende & $\mathrm{SI}$ & SI \\
\hline Startup liviano & $\mathrm{SI}$ & NO \\
\hline Liderazgo & $\mathrm{SI}$ & SI \\
\hline Logística y gestión de cadena de abastecimiento & $\mathrm{SI}$ & SI \\
\hline Mala gestión de carrera & SI & SI \\
\hline Management (como técnica de dirección y gestión de empresas) & $\mathrm{SI}$ & SI \\
\hline Managing (como autoridad o control administrativo) & $\mathrm{SI}$ & SI \\
\hline Mercadeo estratégico & SI & SI \\
\hline Modelo de negocios & SI & NO \\
\hline Modelos organizacionales & SI & SI \\
\hline Modelos negocio & $\mathrm{SI}$ & SI \\
\hline Motivación y trabajo en equipo & $\mathrm{SI}$ & SI \\
\hline Principios administración & $\mathrm{SI}$ & SI \\
\hline Prospectiva/futurología & $\mathrm{SI}$ & SI \\
\hline Reestructuración & $\mathrm{SI}$ & SI \\
\hline Reingeniería & $\mathrm{SI}$ & SI \\
\hline Responsabilidad social empresarial y ambiental & SI & SI \\
\hline Diseño de experiencias de usuario ux - lean ux & SI & NO \\
\hline
\end{tabular}

El anterior análisis brinda una información valiosa dado que las temáticas sin explorar representan una oportunidad única para Generar diferenciación en construcción de Conocimiento.
Algunos ejemplos y que están enmarcados en tendencias actuales son los Modelos de Negocio, Desarrollo de Cliente, Lean Startup, Arquitectura de Negocios y Co-creación entre otras. 
LÍNEA DE INVESTIGACIÓN: COMPETITIVIDAD DE EMPRESAS CONSTRUCTORAS

\section{RESULTADOS DEL ANÁLISIS DE EXPERTOS}

En el ejercicio de análisis de expertos se indagó básicamente acerca de la posibilidad de incluir dentro de la investigación relacionada con la gestión de Empresas constructoras, las temáticas que aún no presentan desarrollo alguno según el material y las bases de datos que se usaron de consulta.

Dentro del ejercicio se realizaron dos rondas para resolver los posibles disensos presentados entre los expertos, en relación a las temáticas que fueron sometidas a análisis para determinar si presentaban un potencial grado de aplicabilidad a la investigación y/o Gerencia de Empresas Constructoras.

Dichas temáticas son:

Arquitectura Negocios

Modelado de Procesos de Negocio (BPM)

Inteligencia De Negocios (Analytics)

Capacidades Dinámicas

Co-Creación

Desarrollo Cliente

Startup Liviano

Modelo De Negocios

Diseño De Experiencias De Usuario (Ux Lean Ux)

Los resultados de la consulta de expertos se presentan a continuación de manera resumida:

1. El Modelo de Negocios propuesto por Osterwalder y Pigneur.

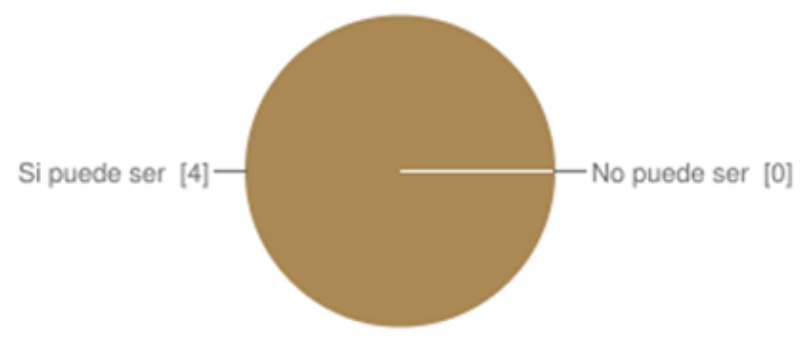

\begin{tabular}{|l|l|c|}
\hline Si puede ser utilizada & $\mathbf{4}$ & $100 \%$ \\
\hline No puede ser utilizada & $\mathbf{0}$ & $0 \%$ \\
\hline
\end{tabular}

2. La Metodología Lean Startup propuesta por Eric Ries.

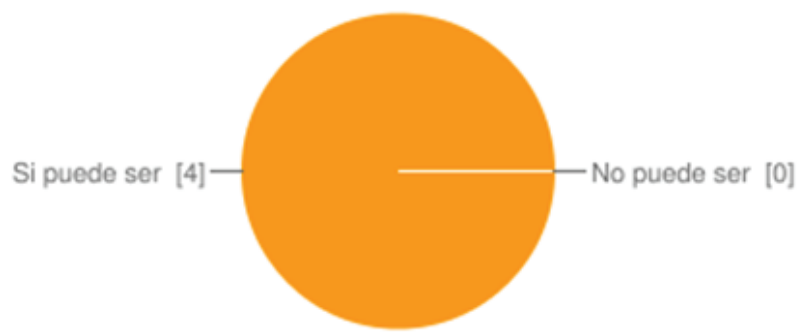

\begin{tabular}{|l|c|c|}
\hline Si puede ser Implementada & $\mathbf{4}$ & $100 \%$ \\
\hline No puede ser Implementada & $\mathbf{0}$ & $0 \%$ \\
\hline
\end{tabular}

3. El Desarrollo de Clientes propuesta por Steve Blank.

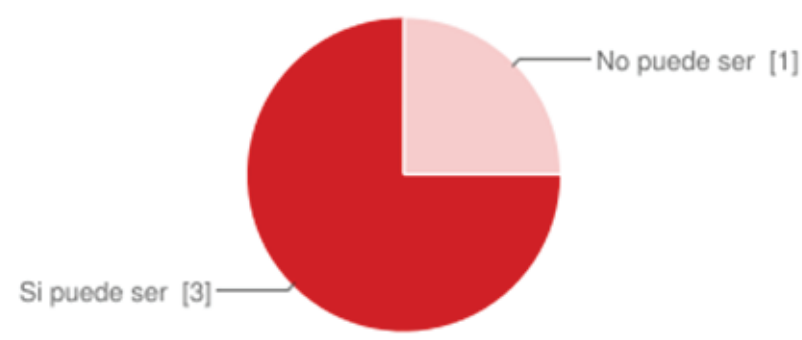

\begin{tabular}{|l|l|l|}
\hline Si puede ser Implementada & $\mathbf{3}$ & $75 \%$ \\
\hline No puede ser Implementada & $\mathbf{1}$ & $25 \%$ \\
\hline
\end{tabular}

4. La Implementación de Sistemas de Información Gerencial, la Inteligencia de Negocios, el Analytics, o la Minería de Datos.

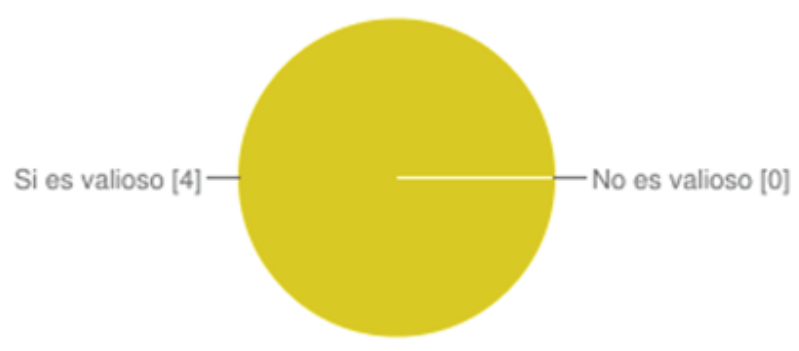

\begin{tabular}{|l|l|l|}
\hline $\begin{array}{l}\text { Si es valioso implementar este tipo de } \\
\text { sistemas }\end{array}$ & $\mathbf{4}$ & $100 \%$ \\
\hline $\begin{array}{l}\text { No es valioso implementar este tipo } \\
\text { de sistemas }\end{array}$ & $\mathbf{0}$ & $0 \%$ \\
\hline
\end{tabular}


5. La re-definición de la Arquitectura del Negocio, o la implementación de Modelos de Gestión de Procesos (BPM).

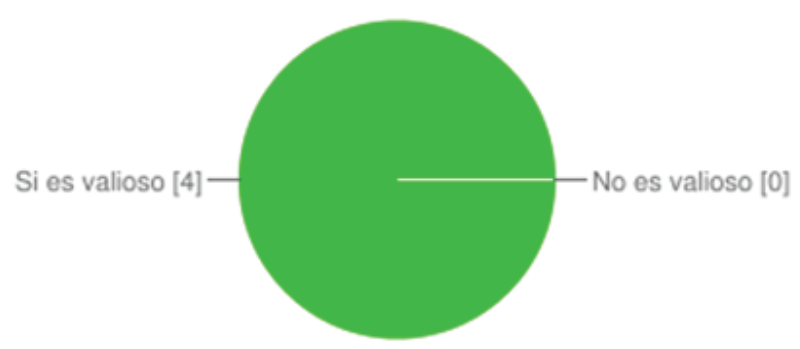

\begin{tabular}{|l|c|c|}
\hline $\begin{array}{l}\text { Si es valioso implementar este tipo de } \\
\text { sistemas }\end{array}$ & $\mathbf{4}$ & $100 \%$ \\
\hline $\begin{array}{l}\text { No es valioso implementar este tipo de } \\
\text { modelos }\end{array}$ & $\mathbf{0}$ & $0 \%$ \\
\hline
\end{tabular}

6. Las estrategias de Co-creación con el cliente.

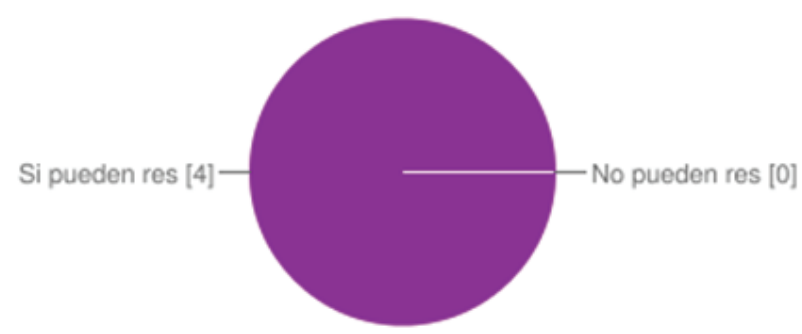

\begin{tabular}{|l|c|c|}
\hline Si pueden resultar exitosas & $\mathbf{4}$ & $100 \%$ \\
\hline No pueden resultar exitosas & $\mathbf{0}$ & $0 \%$ \\
\hline
\end{tabular}

7. Los ejercicios de Planeación Estratégica y de análisis de capacidades Dinámicas.

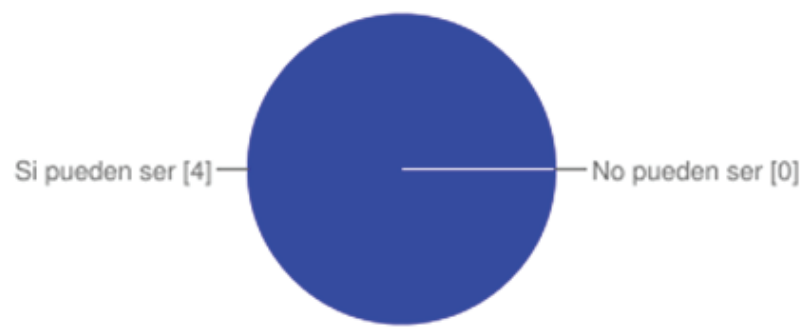

\begin{tabular}{|l|c|c|}
\hline Si pueden ser implementadas con éxito & $\mathbf{4}$ & $100 \%$ \\
\hline No pueden ser implementadas con éxito & $\mathbf{0}$ & $0 \%$ \\
\hline
\end{tabular}

8. Experiencias de Usuario (UX, Lean UX).

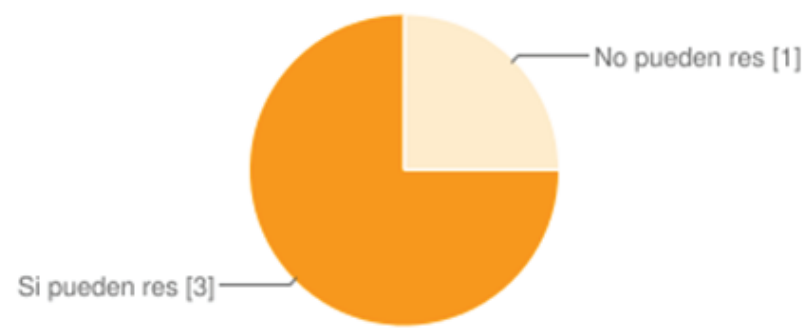

\begin{tabular}{|l|l|l|}
\hline Si pueden resultar efectivas & $\mathbf{3}$ & $75 \%$ \\
\hline No pueden resultar efectivas & $\mathbf{1}$ & $25 \%$ \\
\hline
\end{tabular}

En la Primera Ronda solamente se presentó disenso sobre la metodología de desarrollo de clientes y el diseño de experiencias de usuario (UX), pero luego de una argumentación epistemológica un poco más sólida, se llegó a la conclusión de que efectivamente podría llegar a tener un importante grado de aplicación en proyectos particulares de construcción de inmuebles familiares y proyectos empresariales.

Se puede observar entonces, que de acuerdo con este ejercicio de consulta de expertos, la mayoría de las prácticas de gestión y administración moderna analizadas tienen potencial aplicabilidad a la investigación o a la Gestión en el sector de las empresas Constructoras en Colombia.

\section{CONCLUSIONES Y RECOMENDACIONES}

El enfoque descriptivo tiene un carácter positivista y toma una posición objetiva basada en resultados pasados que han sido efectivos, lo cual clásicamente ha construido un cuerpo de conocimiento basando sus análisis en un sesgo inexorable y paradójicamente subjetivo. Por tanto, es determinante, construir un cuerpo de conocimiento que combine tanto el enfoque descriptivo como normativo para brindar un carácter sistémico al estudio.

Ligado a esto, y dado que se ha perdido el sentido de análisis crítico sobre teorías que 
LÍNEA DE INVESTIGACIÓN: COMPETITIVIDAD DE EMPRESAS CONSTRUCTORAS

pueden ser susceptibles de mejora o adaptación dada la gran dinámica de mercados y entornos, es determinante retomar la discusión académica para construir modelos y prácticas generales que demuestren su aplicabilidad independientemente del entorno.

Dentro del análisis realizado, se observa una tendencia marcada de desarrollo teórico-conceptual en el campo de la operación o Gestión de proyectos, tales como la gestión de recursos financieros, gestión del Riesgo, seguridad industrial, implementación de sistemas de calidad, gestión de almacén y logística de proveedores, y gestión del Talento Humano entre otras. Pero por otro lado, se evidencia la inexistencia de aportes en algunas temáticas contemporáneas que tienen un elevado potencial de desarrollo en el Sector de la Construcción. Este documento, exhorta a la exploración, implementación y desarrollo de éstas tanto en ámbitos académicos como empresariales.

En el ejercicio de validación de Expertos, se sometieron a discusión algunas de las temá- ticas que más fuerza y acogida han tenido en los últimos años en el ámbito Empresarial, y se identificó que metodologías como el Modelo de Negocios, el Diseño de experiencia de Usuario, el modelamiento de procesos de Negocio, la Arquitectura de Negocios, la Inteligencia de Negocios, los modelos de Co-creación, el Desarrollo del Cliente, pensamiento de diseño, los ejercicios de planeación estratégica y el análisis y desarrollo de capacidades dinámicas tienen un elevado potencial de aplicación al Sector de las Empresas Constructoras.

Con el surgimiento permanente de nuevos Modelos o Metodologías de Gestión y Administración Empresarial, el reto que surge para las Empresas de Cualquier sector o Región, es el de experimentar y validad la potencial aplicabilidad de éstas en sus ámbitos particulares. Por tanto se espera que de esta primera aproximación, se desprendan nuevas investigaciones y que quienes tienen la ardua labor de dirigir organizaciones contemplen la posibilidad de participar activamente en el desarrollo y ajuste de estas nuevas herramientas gerenciales.

\section{REFERENCIAS}

Afuah, A. (2003). Innovation management: Strategies, implementation and profits.

Allan, A., \& Christopher, T. (2001). Internet business models and strategies.

Ansoff, I. (1984). Corporate strategy. New York: McGraw Hill.

Argyris, C. (1957). Personality and organization. New York: Harper.

Argyris, C., \& Schön, D. (1978). Organizational learning. New York: Addison Wesley.
Ballard, G., \& Howell, G. (2003). Lean project management. Building Research \& Information, 31(2), 119-133.

Bennis, W., \& Nanus, B. (1985). Leaders: The strategies fot taking charge. New York: Harper \& Row.

Bertoglio, O. J. (1982). Anatomía de la empresa: Una teoría general de las organizaciones sociales Editorial Limusa.

Blank, S. G. (2007). The four steps to the epiphany

Bodine, P. A., \& Hilty, J. (2009). Business architecture:
An emerging profession. Business Architects Association Institute,

Bowen, H. R. (2013). Social responsibilities of the businessman University of lowa Press.

Carroll, A. B. (1991). The pyramid of corporate social responsibility: Toward the moral management of organizational stakeholders. Business Horizons, 34(4), 39-48.

Chandler, A. (1962). Estrategia y estructura. Boston, M.A.: MIT Press.

Christensen, C. R., Andrews, K. R., Bower, J. L., Ha- 
mermesh, R. G., \& Porter, M. E. (1965). Business policy: Text and cases RD Irwin.

Cooper, B., \& Vlaskovits, P. (2010). The entrepreneur's guide to customer development Custdev.

Daum, J. (2005). French tableau de bord: Better than the balanced scorecard. Der Controlling Berater, 7

David, D. K. (1949). Business responsibilities in an uncertain world

de Guerny, J., Guiriec, J., \& Lavergne, J. (1990). Principes et mise en place du tableau de bord de gestion Delmas.

Dempsey, B. W. (1958). The functional economy: The bases of economic organization Englewood Cliffs (NJ): PrenticeHall.

Drucker, P. (1973). The practice of management. New York: Harper \& Row.

Fisk, P. (2009). Marketing genius John Wiley \& Sons.

Frederick, W. C. (1988). Business and society: Corporate strategy, public policy, ethics McGraw-Hill Companies.

Ghoshal, S., \& Bartlett, C. (1997). Managing across borders. Boston M.A: Harvard Business School Press.
Gilfillan, S. C. (1970). The sociology of invention: An essay in the social causes, ways, and effects of technic invention, especially as demonstrated historicly [sic] in the author's inventing the ship MIT press.

Gothelf, J. (2013). Lean UX: Applying lean principles to improve user experience " O'Reilly Media, Inc.".

Hamel, G. (2002). Leading the revolution: How to thrive in turbulent times by making innovation a way of life Harvard Business School Press Boston.

Hamel, G., \& Prahalad, C. K. (1994). Competing for the future. Cambridge, M.A.: Harvard university Press.

Handy, C. (1976). Undestranting organizations. London: Penguin Books.

Hart, H. (1931). The technique of social progress $\mathrm{H}$. Holt.

Heald, M. (1970). The social responsibilities of business: Company and community 19001960 Transaction Publishers.

Herzberg, F., Mausner, B., \& Snyderman, B. (1959). The motivation to work. New York: Wiley.

Hofstede, G. (1984). Culture's consequences: International differences in work-related values Sage Publications.
Jaques, E. (1976). A general theory of bureaucracy. New York: Wiley.

Jensen, M., \& Meckling, W. (1976). Theory of the firm: Managerial behavior. Agency Costs and Ownership Structure, nJournal of Financial Economics, 3(4), 305.

Kaplan, R. S., \& Norton, D. P. (1996). The balanced scorecard: Translating strategy into action Harvard Business Press.

Kelley, D., Neck, H. M., O'Connor,G.C., \& ... (2005). Corporate entrepreneurship through radical innovation: Key organization and initiative level mechanisms. $\hat{A} €_{\mathrm{I}}$ Entrepreneurship and $\hat{A} €$,

Kotler, P. (1997). Marketing management (9 ed. ed.) Prentince Hall.

Le Moigne, J. L. (1997). La incoherencia epistemológica de las ciencias de la gestión (traducción). Revista Cuadernos De Economía,

Levitt, T. (1962). Innovation in marketing. New York: Mc Graw Hill.

Levitt, T. (1974). The manager merry go-round. Harvard Business Review, Julio-Agosto, 120.

Lewin, K. (1935). A dynamivc theory of personality. New York: McGraw Hill. 
LÍNEA DE INVESTIGACIÓN: COMPETITIVIDAD DE EMPRESAS CONSTRUCTORAS

Luhmann, N. (2010). The power

Lusk, S., Paley, S., \& Spanyi, A. (2005). The evolution of business process management as a professional discipline. BP Trends,[Online] Available at: $<\quad$ Http://Www.Bptrends. Com/Publicationfiles/06-05\% 20WP\% 20ABPMP\% 20Activities, 20

Maslow, A. (1987). Motivation and personality (3 ed. ed.). New York: Harper \& Row.

Maurya, A. (2012). Running lean: Itetate from plan $A$ to a plan that works O'Reilly.

Mayo, E. (1933). The human problems of an industrial civilization. New York: Macmillan,.

McGregor, D. (1960). The human side of enterprise. New York: McGraw Hill.

Mintzberg, H. (1976). EL PODER EN LA ORGANIZACION

Mintzberg, H., \& Quinn, J. B. (1991). The strategy process: Concepts, contexts, cases (2nd Edition ed.). Englewood Cliffs, NJ: Prentice Hall.

Moore, G. A. (2005). Dealing with darwin. New York: Pinguin Group,

Moss Kanter, R. (1983). The change maters. New York: Simon \& Schuster.
Naisbitt, J. (1984). Megatrends Warner Books.

OECD, \& Eurostat. (2005). Manual de oslo

Ogburn, W. F. (1937). National policy and technology. J.Pat.Off.Soc'Y, 19, 546.

Osterwalder, A., Pigneur, Y., \& Smith, A. (2005). Business model generation Wiley \& sons.

Parker F., M. (1941). Dynamic administration. New York: Harper \& Brothers.

Pascale, R. (1990). Managing on the edge. London: $\mathrm{Vi}-$ king.

Penrose, E. T. (1995). The theory of the growth of the firm Oxford university press.

Peter, L., \& Hull, R. (1969). The peter principle. New York: William Morrow \& Co.

Peters, T., \& Rodabaugh, K. (1988). Thriving on chaos: Handbook for a management revolution. The Journal of Continuing Higher Education, 36(2), 27-28.

Porter, M. (1985). Competitive advantage. New York: Free Press.

Porter, M. E. (1987). From competitive advantage to corporate strategy Harvard Business Review Cambridge, MA.
Ries, E. (2011). The lean startup Crown Business.

Sartori, G., \& Lara, M. (1984). La política: Lógica y método en las ciencias sociales Fondo de Cultura Económica México^ $^{\wedge}$ D. F DF.

Schein, E. (1985). Organizational culture and leadership. San Francisco: Jossey Bass.

Schumpeter, J. A. (2000). Entrepreneurship as innovation. Entrepreneurship: The Social Science View,

Schumpeter, J. (1934). The theory of economic development. New York: McGraw-Hill.

Senge, P. (1990). The fifth discipline, the art and practice of the learning organization. New York: Doubleday.

Sibbet, D. (2008). Visual intelligence: Using the deep patterns of visual language to build cognitive skills. Theory into Practice, 47(2), 118-127.

Simon, H. A. (1965). Administrative behavior Cambridge Univ Press.

Sternberg, R. (2007). Entrepreneurship, proximity and regional innovation systems. Tijdschrift Voor Economische En Sociale Geografie,

STERNBERG, R., PRETZ, J., \& KAUFMAN, J. (2003). Types of innovation. (pp. 12-12) 
Taylor, F. W., \& Fayol, H. STRATEGIC MANAGEMENT (1977). Principios de la admi- OXFORD. nistración científica.

Taylor, H. F. (1911). PRIN- wave. New York: Bantam. CIPLE OF MANAGEMENT.

Trompenaars, F., \& Hamp-

Teece, D. J. (2009). DI- den-Turner, C. (1994). Riding NAMIC CAPABILITIES AND the waves of culture. London:

\section{Piatkus.
PiMIC CAPABILITIES AND}

Weber, M. (1947). The theory of social and economic organization. New York: Free Press.

Williamson, O. E. (1975). Markets and hierarchies. New York, 26-30. 